\title{
Validation and Verification Methodology for INL Modelica- based TEDS Models Via Experimental Results
}

September | 2021

Konor L Frick

Shannon Bragg-Sitton

Idaho National Laboratory

Marisol Garrouste

University of Michigan
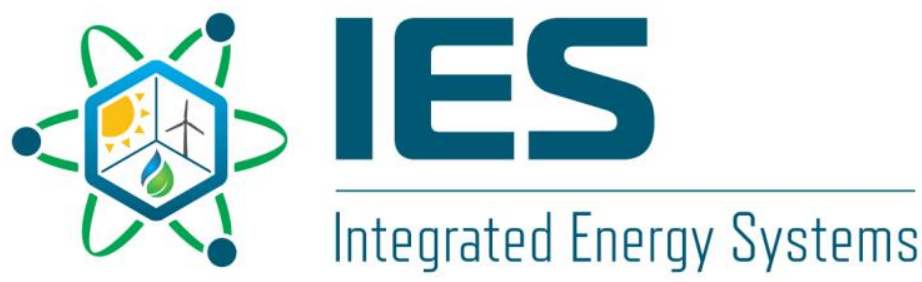


\section{DISCLAIMER}

This information was prepared as an account of work sponsored by an agency of the U.S. Government. Neither the U.S. Government nor any agency thereof, nor any of their employees, makes any warranty, expressed or implied, or assumes any legal liability or responsibility for the accuracy, completeness, or usefulness, of any information, apparatus, product, or process disclosed, or represents that its use would not infringe privately owned rights. References herein to any specific commercial product, process, or service by trade name, trade mark, manufacturer, or otherwise, does not necessarily constitute or imply its endorsement, recommendation, or favoring by the U.S. Government or any agency thereof. The views and opinions of authors expressed herein do not necessarily state or reflect those of the U.S. Government or any agency thereof. 


\title{
Validation and Verification Methodology for INL Modelica-based TEDS Models Via Experimental Results
}

\author{
Konor L Frick \\ Shannon Bragg-Sitton \\ Idaho National Laboratory \\ Marisol Garrouste \\ University of Michigan \\ September 2021
}

Idaho National Laboratory Integrated Energy Systems Idaho Falls, Idaho 83415

http://www.ies.inl.gov

Prepared for the

U.S. Department of Energy

Office of Nuclear Energy

Under DOE Idaho Operations Office

Contract DE-AC07-05ID14517 
Page intentionally left blank 


\section{ABSTRACT}

This report provides an overview on the verification and validation $(\mathrm{V} \& \mathrm{~V})$ of the Thermal Energy Distribution System (TEDS) model developed in the Modelica process modeling ecosystem using experimental data.

Model development has led to the creation of a dynamic process model of the experimental TEDS facility housed within the Energy Systems Laboratory (ESL) at Idaho National Laboratory (INL). The model was then used during the preconstruction phase of the experimental effort to inform experimental design (e.g., insulation requirements, bypass line placement, expected performance of components) and to test innovative control schemes prior to the initial operation. The TEDS model developed in Modelica includes the primary components of the TEDS experimental unit: a 200kW Chromalox heater; a single-tank packed-bed thermal energy storage system filled with 0.125 -inch alumina $\left(\mathrm{Al}_{2} \mathrm{O}_{3}\right)$ beads; an ethylene-glycol-to-Therminol-66 heat exchanger; system piping; five control valves; and all associated temperature, pressure, and volumetric flow sensors.

Using the Institute of Electrical and Electronics Engineers (IEEE) V\&V methodologies, considered the gold standard in the engineering field, the model was verified using a combination of static analysis, spatial convergence, and regression tests. Then using dynamic time warping (DTW) initial runs to validate and tune the TEDS model versus the experiment were conducted. This tuning method was accomplished using the INL Risk Analysis Virtual ENvironment (RAVEN) software package. Tuning is required to account for physical phenomena that are less understood within the empirical heat transfer correlations.

Through the commencement of this work, a systems-level model of TEDS with associated control systems, sensors, piping diameters, and component capabilities has been created. This model was utilized in the pre-experimental phase to inform system design, insulation thicknesses, and potential control schemes to operate the system effectively and safely. Then, initial experimental startup and operational data were used to demonstrate the validation and tuning methodology. This process demonstrates the classical two-step approach of a model informing experimental design followed by the experiment validation and tuning the model. 
Page intentionally left blank 


\section{CONTENTS}

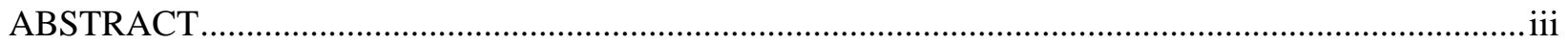

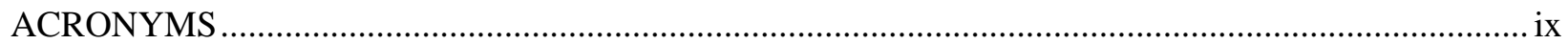

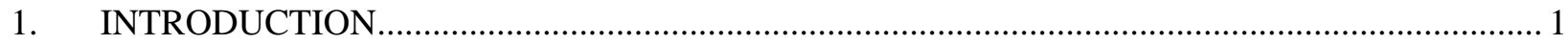

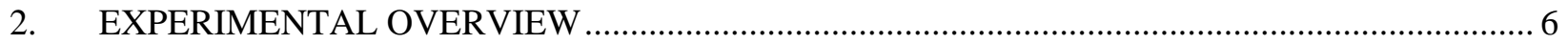

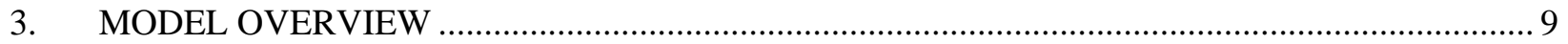

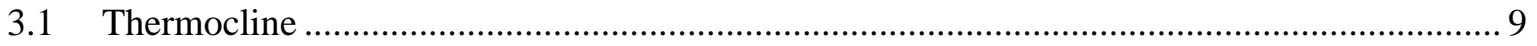

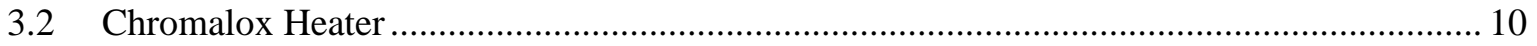

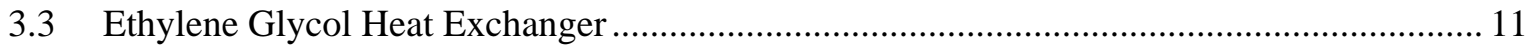

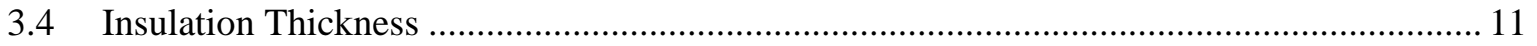

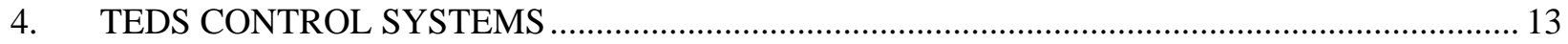

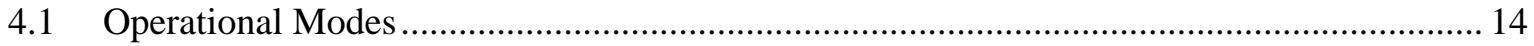

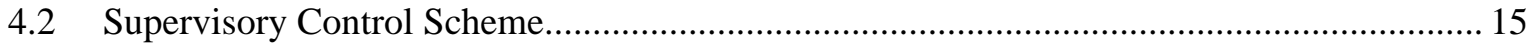

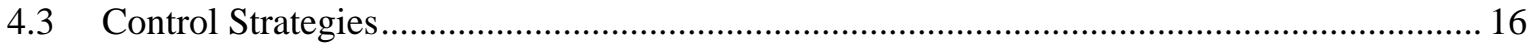

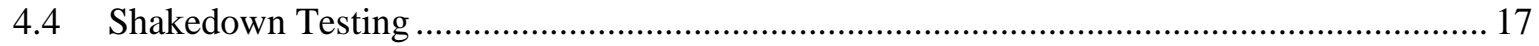

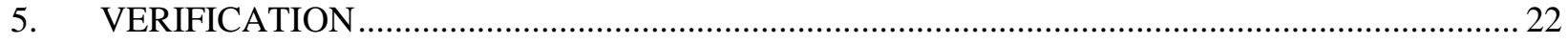

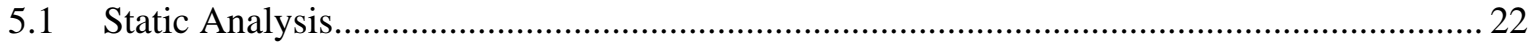

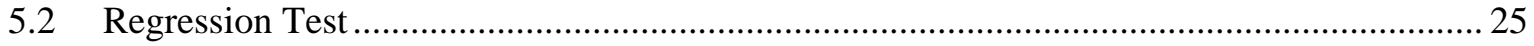

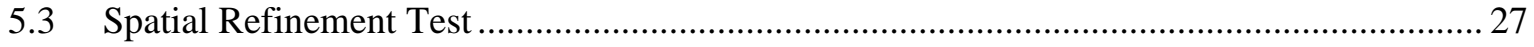

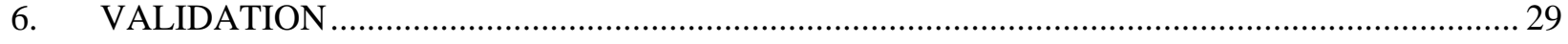

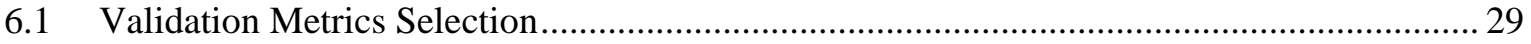

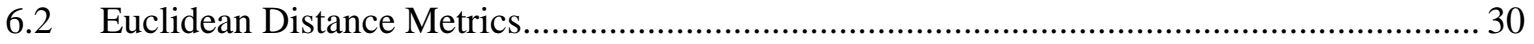

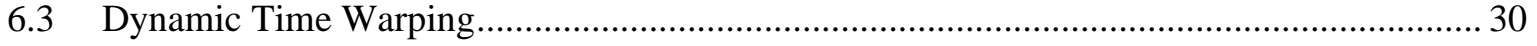

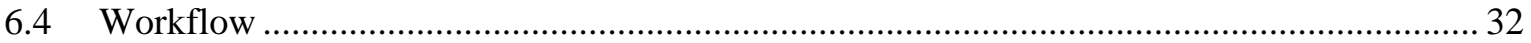

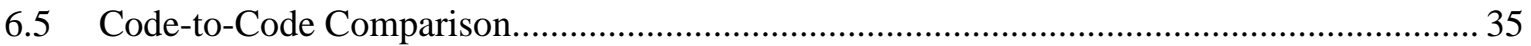

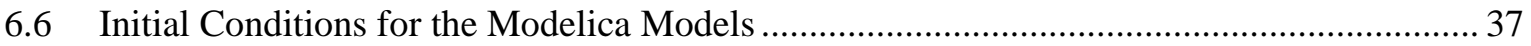

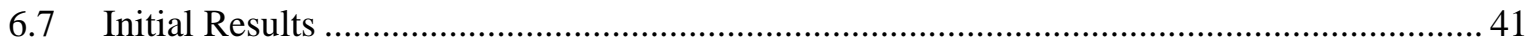

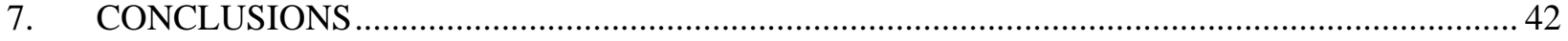

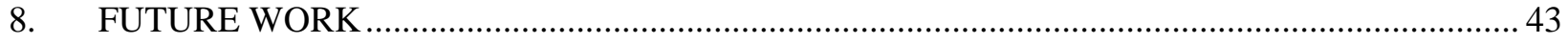

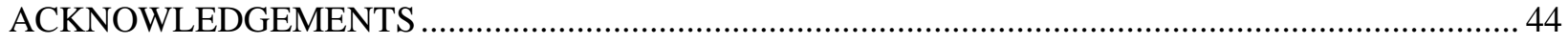

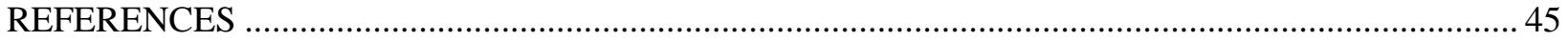




\section{FIGURES}

Figure 1. Example architecture for IES.

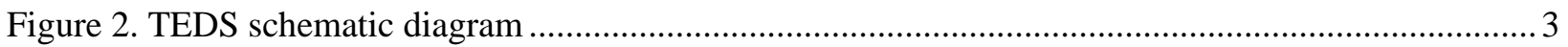

Figure 3. TEDS piping and instrumentation (P\&ID) diagram........................................................

Figure 4. Graham Heliflow heat exchanger installed on the TEDS....................................................... 7

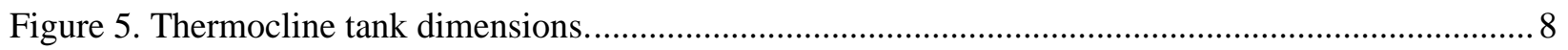

Figure 6. Nodal representation of thermocline model from Modelica..................................................... 10

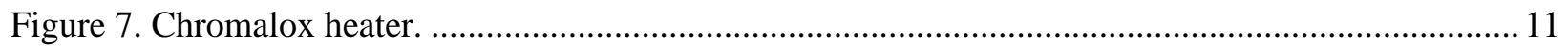

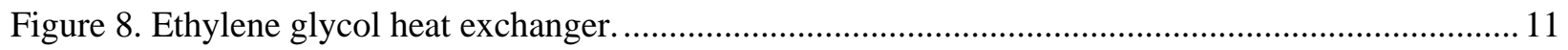

Figure 9. Thermocline temperatures with varying levels of insulation.................................................. 12

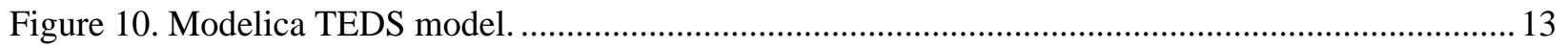

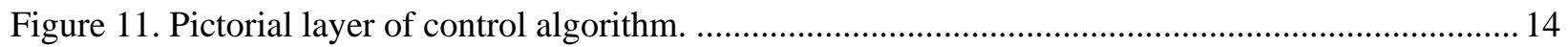

Figure 12. (Top) System demand on heater, thermocline, and total system. (Bottom) Calculated thermocline fluid temperature at varying points within the tank ............................................. 19

Figure 13. (Top) Chromalox heater input. (Bottom) Calculated temperatures throughout the

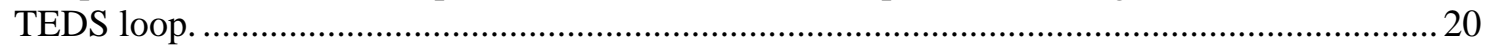

Figure 14. (Top) BOP mass flow rate. (Bottom) TES mass flow rates vs. sensor reading........................ 21

Figure 15. Compilation pathway within Modelica when a code is told to simulate. The user only needs to develop the Modelica source code. 23

Figure 16. Log file generated inside Dymola 2021x describing the equation set when the "check"

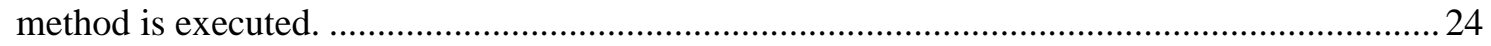

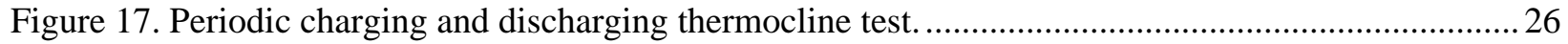

Figure 18. Fluid and filler temperature at axial locations of $i=1$ (top of tank), $i=50$ ( $25 \%$ down the tank), $i=100$ (50\% down the tank), $i=150$ (75\% down the tank), and $i=200$ (bottom of

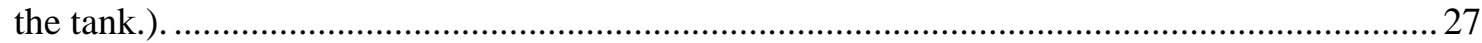

Figure 19. GCI function of mesh refinement and elevation in the thermocline tank.............................28

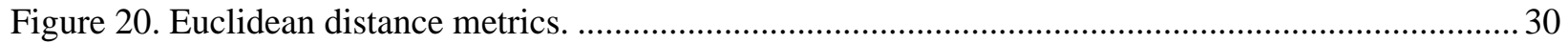

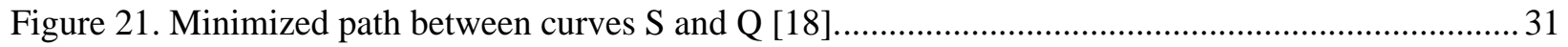

Figure 22. DTW mapping of S and Q for normalized power demand................................................ 32

Figure 23. RAVEN V\&V workflow for comparing classical metrics................................................... 33

Figure 24. RAVEN V\&V workflow using DTW as the comparison metric. ........................................... 34

Figure 25. Example RAVEN XML workflow for the validation of classical metrics............................. 35

Figure 26. TEDS code-to-code comparison. DTW distance between the reference data (porosity = 0.9 ) and the model data (TC-1, thermocline top temperature; and TC-4, thermocline bottom temperature) function of the thermocline porosity. 
Figure 27. TEDS code-to-code comparison. DTW distance between the reference data (shape factor $=3.5)$ and the model data (TC-4, thermocline bottom temperature) function of the thermocline shape factor.

Figure 28. Valve opening signals and volume flow rate through valve 1 and 4 during charging run to $100^{\circ} \mathrm{F}$.

Figure 29. Temperatures in the thermocline and on the charging line during charging.

Figure 30. Valve opening signals and volume flow rate through valves 3 and 5 during step 8 of the test matrix.

Figure 31. Temperatures in the thermocline during step 8 of the test matrix.

Figure 32. DTW optimization metric for thermocline porosity as a function of the thermocline exit temperature (TC-4).

Figure 33. Thermocline exit temperature from the initial simulation point with a porosity of 0.5 to the end point of porosity 0.2 . 


\section{TABLES}

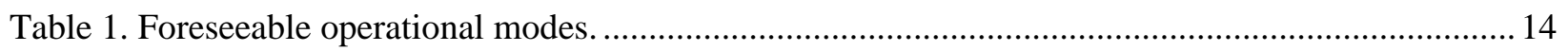

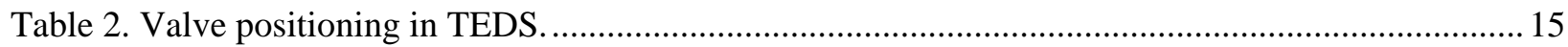

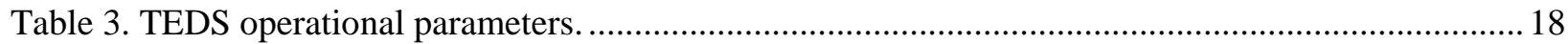

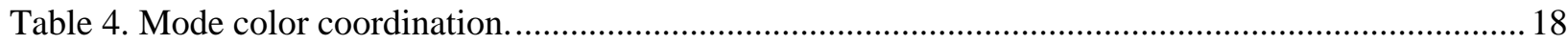

Table 5. Static testing checklist conducted on the TEDS model. ........................................................... 24

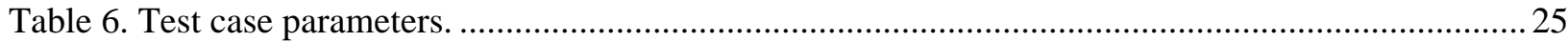




\section{ACRONYMS}

\begin{tabular}{|c|c|}
\hline $\mathrm{Al}_{2} \mathrm{O}_{3}$ & alumina \\
\hline ANS & American Nuclear Society \\
\hline ASME & American Society of Mechanical Engineers \\
\hline BOP & balance of plant \\
\hline BV & ball valve \\
\hline CFD & computational fluid dynamics \\
\hline DAE & differential algebraic equation \\
\hline DETAIL & Dynamic Energy Transport and Integration Laboratory \\
\hline DRTS & Digital Real-Time Simulation \\
\hline DTW & dynamic time warping \\
\hline Dymola & Dynamic Modeling Laboratory \\
\hline ESL & Energy System Laboratory \\
\hline FM & flow meter \\
\hline GBV & globe valve \\
\hline GCI & Grid Convergence Index \\
\hline GUI & graphical user interface \\
\hline IEEE & Institute of Electrical and Electronics Engineers \\
\hline IES & Integrated Energy Systems \\
\hline INL & Idaho National Laboratory \\
\hline IRIS & International Reactor Innovative and Secure \\
\hline $\mathrm{M} \& \mathrm{~S}$ & modeling and simulation \\
\hline NPS & nominal pipe size \\
\hline ORNL & Oak Ridge National Laboratory \\
\hline $\mathrm{P}$ & proportional controller \\
\hline P\&ID & piping and instrumentation \\
\hline PI & proportional integral controller \\
\hline PID & proportional integral derivative controller \\
\hline RAVEN & Risk Analysis Virtual ENvironment \\
\hline TC & thermocouple \\
\hline TEDS & Thermal Energy Distribution System \\
\hline TES & Thermal Energy Storage \\
\hline $\mathrm{V} \& \mathrm{~V}$ & verification and validation \\
\hline VFD & variable frequency drive \\
\hline
\end{tabular}


Page intentionally left blank 


\section{INTRODUCTION}

Grid demand variability is a byproduct of the modern dynamic lifestyle. The addition of renewable energy technologies, such as wind and solar, introduces variability into the grid supply. As renewable integration continues, variability increases. The Integrated Energy Systems (IES) program, led by Idaho National Laboratory (INL), is researching these effects. IES involves the design, integration, and coordinated operation of several complex, standalone systems. The control algorithms involved are unique to each application and the design of the components. IES architecture can include process steam applications, thermal energy storage, and the presence of intermittent energy sources such as wind and solar, as shown in Figure 1.

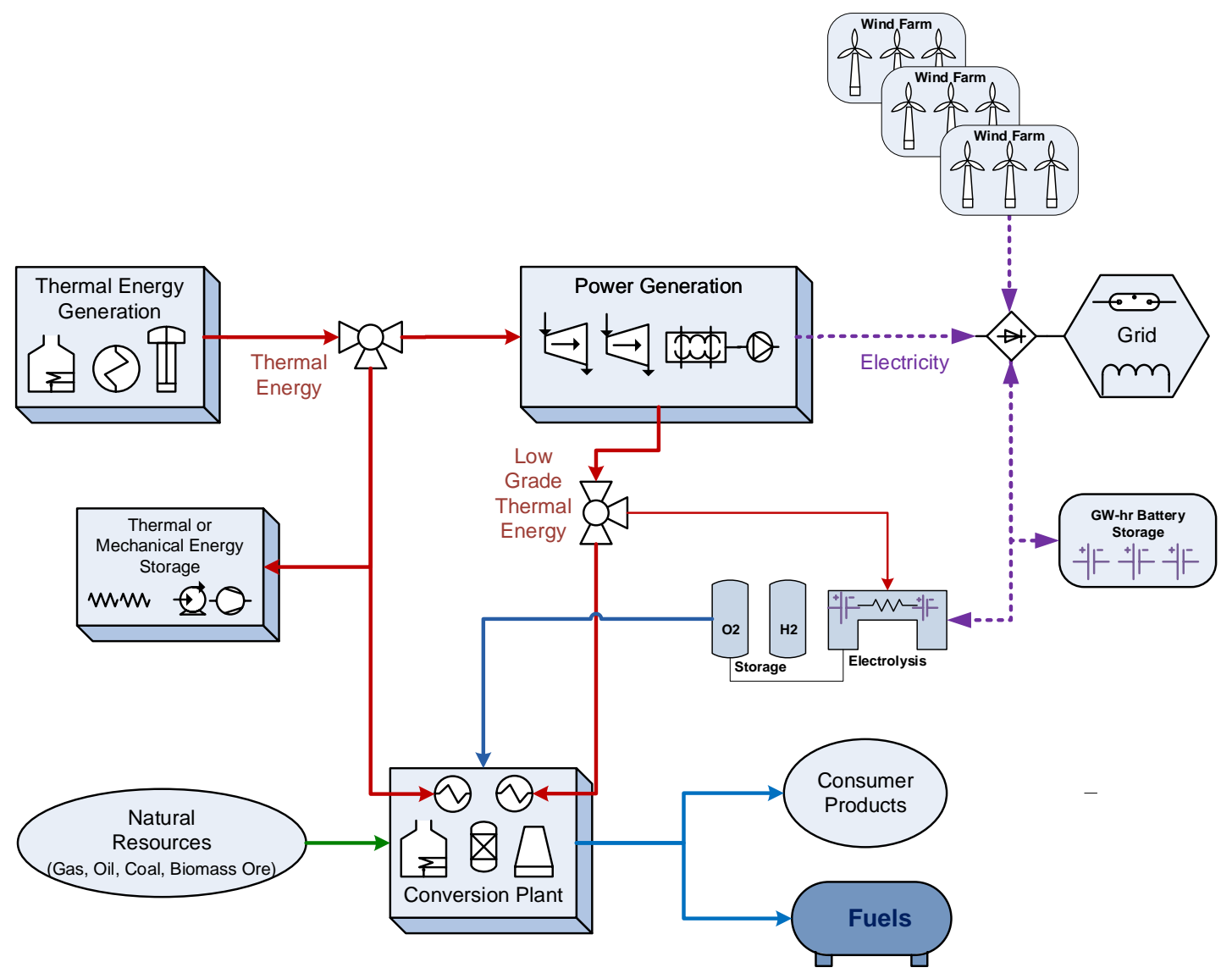

Figure 1. Example architecture for IES.

The goal of these systems is to operate as economically and efficiently as possible. For integrated energy parks that incorporate thermal energy storage, this means operating thermal generators at full power and storing excess energy for later use during times of low total demand and discharging that energy during times of high demand.

To accommodate the vast array of possibilities introduced in integrated energy parks, INL has been developing a library of high-fidelity process models in the Modelica modeling language [1-4]. The Modelica language is a non-proprietary, object-oriented, equation-based language used to conveniently model complex, physical systems. Modelica is an inherently time-dependent modeling language that allows the swift interconnection of independently developed models. Being an equation-based modeling language that employs differential algebraic equation (DAE) solvers, users can focus on the physics of the problem rather than the solving technique, allowing faster model generation and, ultimately, analysis. This feature 
alongside system flexibility has led to the widespread use of the Modelica language across industry for commercial applications. System interconnectivity and the ability to quickly develop novel control strategies while still encompassing overall system physics is why INL has chosen to develop the IES framework in the Modelica language.

Current models include thermal energy storage, reverse osmosis, four-loop nuclear power plants, the International Reactor Innovative and Secure (IRIS) reactor, natural gas turbines, coal plants, hightemperature steam electrolysis, and switchyards. These detailed dynamic models, which are used to create and characterize system inertia, thermal losses, and efficiency of integrated systems, are a cornerstone of the IES simulation framework. These physical models help map physical performance into economic performance, allowing system-level optimization. In addition, these models are used to test innovative system-level control strategies of interconnected thermal generators and energy users.

However, due to limited experimental data, the understanding of the interconnection between systems has been limited. To help address this lack of data, a Dynamic Energy Transport and Integration Laboratory (DETAIL) has been designed and is being installed within the Energy Systems Laboratory at INL to demonstrate integrated system operation. The overall objective for the DETAIL facility is to demonstrate simultaneous, coordinated, and efficient transient distribution of electricity and heat for power generation, energy storage, and industrial end-uses. The combined DETAIL facility will provide demonstration of realtime integration with the electrical grid, renewable energy inputs, thermal energy generation and distribution, thermal and electrical energy storage, and energy delivery to an end user. As such, an integrated energy network can be simulated to improve our understanding of how to optimize energy flows while maintaining system stability and efficient operation of all assets in the system.

The Thermal Energy Distribution System (TEDS), shown in Figure 2, acts as the backbone of the DETAIL facility to test heat transfer components, distribution systems, instrumentation, and controls that can be monitored and controlled for the hybrid generation of electrical power and/or non-electrical products. As is the case for other subsystems within DETAIL, TEDS is designed to operate either independently or as a part of an integrated system. Within the integrated system, TEDS will be connected to the INL Digital Real-Time Simulation (DRTS) test platform to develop and demonstrate monitoring and control systems and to investigate real-time, hardware-in-the loop response characteristics relative to grid operations. The system can be used to characterize thermal energy inertia and thermal energy management relative to the interoperability of power generation, energy storage, and industrial heat applications. 


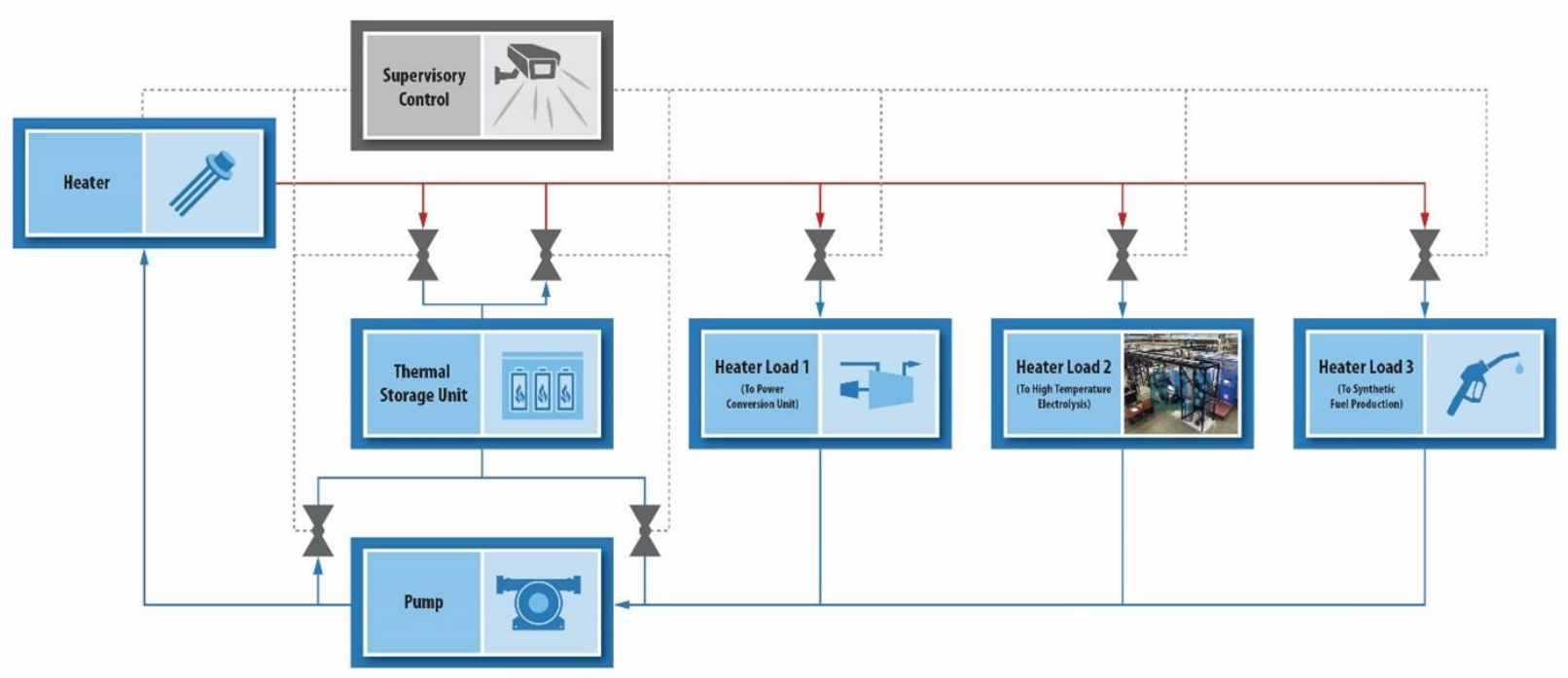

Figure 2. TEDS schematic diagram

To model control algorithms and elucidate potential problem areas, a TEDS model was developed in Modelica-based upon initial design data. The TEDS model was implemented using the commercially available Modelica-based modeling and simulation (M\&S) environment (i.e., a Dynamic Modeling Laboratory [Dymola] version 2021x) [5]. In-house-developed packages and open-source libraries were used to facilitate M\&S. In particular, the Modelica Standard Library version 4.0.0 [6] and TRANSFORM [7] from Oak Ridge National Laboratory (ORNL) were employed. Figure 3 shows an example of a TEMS diagram. The model was then used to inform various aspects of the experimental design from control systems to insulation thickness. Through this transient model development, various operational constraints and potential hiccups could be avoided prior to build. To ensure the operational constraints and hiccups were realistic and not simply issues with the code development process, a verification and validation $(\mathrm{V} \& \mathrm{~V})$ workflow was developed.

$\mathrm{V} \& \mathrm{~V}$ represent important steps in characterizing the usefulness and representativity of a computer model to the developer's intent and physical world. The nuance of $\mathrm{V} \& \mathrm{~V}$ is often unclear, and it is often misrepresented that a code is validated and verified when it is often only one of the two. In 1984, during the infancy of modern $\mathrm{V} \& \mathrm{~V}$, the Institute of Electrical and Electronics Engineers (IEEE) formally developed a definition for $\mathrm{V} \& \mathrm{~V}$ that was adopted by several institutions, including the American Nuclear Society (ANS), the software quality assurance community, and the computer science community. IEEE defines $\mathrm{V} \& \mathrm{~V}$ as follows:

- Verification: the process of evaluating the products of a software development phase to provide assurance that they meet the requirements defined for them by the previous phase.

- Validation: the process of testing a computer program and evaluating the results to ensure compliance with specific requirements.

In other words, verification is the process of checking the design of the code, confirming that the software conforms to specification, and ensuring the code is accurately representing what it was designed to do. Verification does not necessarily involve the execution of the code.

Validation, on the other hand, always involves the execution of the code and checks whether the software meets the requirements and expectations of the customer. It can identify bugs that the verification process cannot and usually involves the computation of various metrics to ensure the code is valid in the 
application domain of interest. For models needing calibration, the validation is an iterative process. If the validation metrics indicate poor model accuracy, modeling parameters can be adjusted to improve agreement with the experimental data and the validation steps repeated for the updated model.

Additionally, it is important to recognize that $\mathrm{V} \& \mathrm{~V}$ is an ongoing activity that does not have a clearly defined completion point, unless additional specifications are given in terms of intended uses of the model and adequacy. For example, one cannot prove that even a moderately complex computer code has no errors. Therefore, it is important to recognize that a regime of applicability can be defined for a given model via prescribed constraints of the underlying physics, computer algorithm tolerances, and solution methodologies, but that it remains an iterative process upon which the regime of applicability is continually expanding. Therefore, a regime of applicability must be developed for TEDS, and the TEDS model can be characterized and certified over this operational space.

Through the creation of a TEDS model and experimental facility, research organizations and industry will be able to demonstrate and test technologies within an experimental facility both digitally and experimentally. In the initial stages, researchers will be able to leverage the existing TEDS Modelica model to test any number of new and unique control strategies, coupling mechanisms, ancillary processes, system sizing, and system response to various externalities, such as market conditions. Researchers and industry partners will then be able to bring their technology into the lab to verify their selected computational permutation and obtain data for $\mathrm{V} \& \mathrm{~V}$ and licensing purposes. This report provides an in-depth view of the experimental facilities, Modelica model, and V\&V process used to benchmark the model for future IES modeling and outreach efforts. 


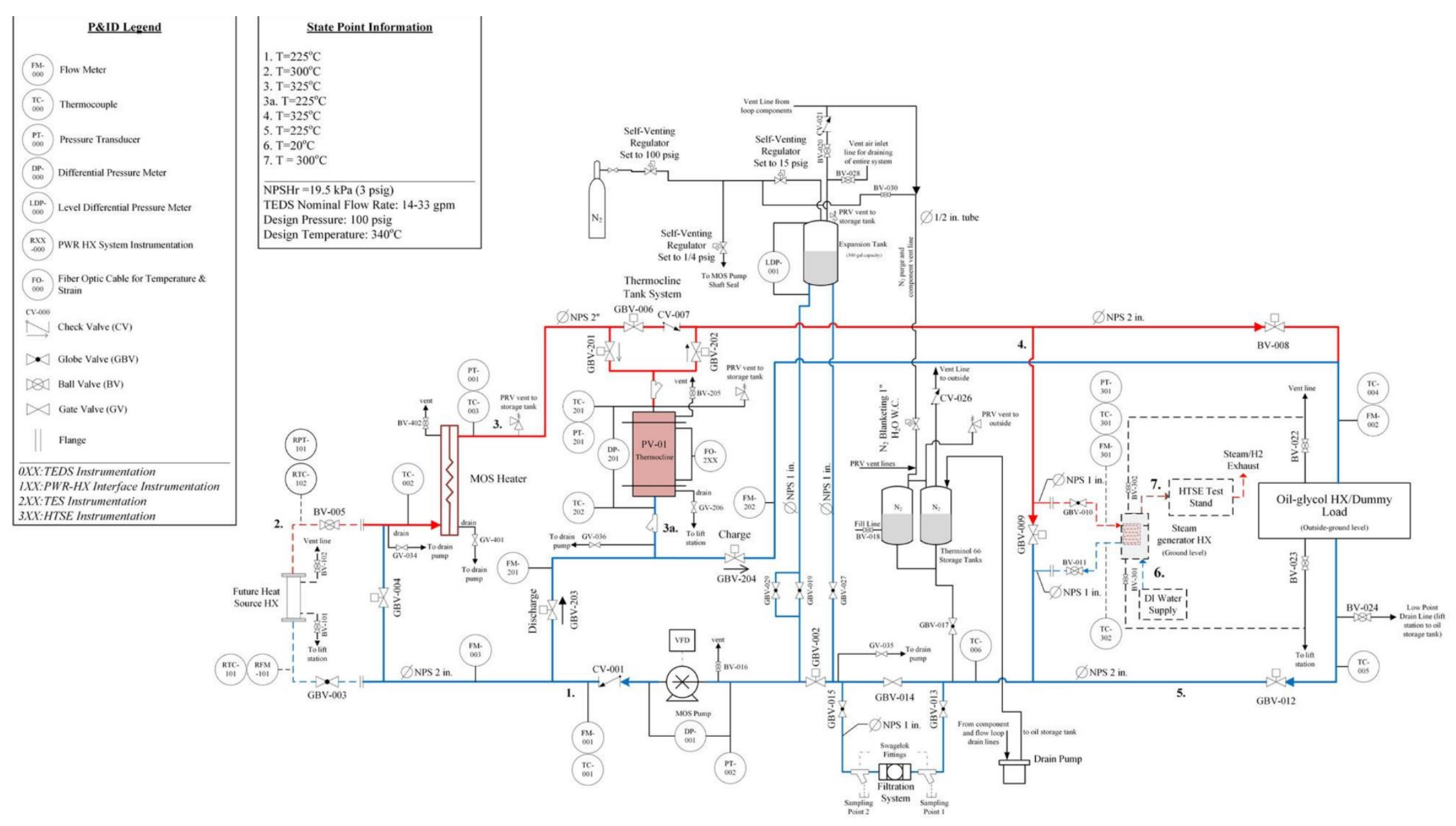

Figure 3. TEDS piping and instrumentation (P\&ID) diagram. 


\section{EXPERIMENTAL OVERVIEW}

TEDS is meant to serve as the thermal energy distribution backbone for an integrated energy system. The initial design basis for TEDS was an integrated energy system that demonstrated the use of high-grade secondary side steam from a pressurized water reactor at temperatures up to $325^{\circ} \mathrm{C}$ (e.g., mid-grade for next generation nuclear plants or natural gas-fired combustion engines). The unit is designed to experimentally demonstrate the mass movement of the thermal energy around a utility complex for use with various ancillary applications (e.g., hydrogen production, thermal energy storage, multi-stage flash desalination, etc.). As a part of this research, it was important to determine and develop a base configuration that was extendable to several new applications.

The TEDS basal configuration consists of a heater system, oil pump, thermocline packed-bed thermal energy storage system, expansion and storage tanks, and an oil-to-glycol heat exchanger. Listed below are the experimental details for each of these components. In addition to these base components, the TEDS facility is outfitted with additional blind manifolds capable of coupling to additional ancillary processes on an "as needed" basis with subsequent controllers capable of plugging into the TEDS software mainframe.

\section{Chromalox Heater}

The Chromalox heater is a $200-\mathrm{kW}$ hot oil heater system with a main hot oil pump procured from Chromalox. The heater is rated up to $343^{\circ} \mathrm{C}\left(650^{\circ} \mathrm{F}\right)$ and is designed per American Society of Mechanical Engineers (ASME) standards. Additionally, the heater is certified up to the design pressure to $100 \mathrm{psig}$. This heater system will initially be the heat source for the loop and bring the oil temperature to its maximum $325^{\circ} \mathrm{C}$ operating temperature. Additional details are available in a 2019 INL report [8].

\section{Main Oil Pump}

A hot oil pump provided by Chromalox drives flow through the system to supply the necessary nominal flowrate ranges of 14-33 gallons per minute (e.g., $0.053-0.125 \mathrm{~m}^{3} / \mathrm{min}$ ). The oil pump can meet the loop design temperature and pressure. The pump uses a $5 \mathrm{hp}$ inverter duty motor with a variable frequency drive (VFD) allowing for controllable flow throughout the predicted system operation. This VFD will be used to control the pump's flowrate and will be adjusted with LabVIEW software.

\section{Piping}

Piping in the TEDS loop is carbon steel, which is compatible with Therminol-66 and can meet the design conditions. This pipe size was selected based on a comparison of pressure drop, fluid velocity, and loop time constant for various nominal pipe sizes (NPSs). Possible sizes ranged from 1 to 3 in. A NPS of $2 \mathrm{in}$. had optimal values for all parameters and offered a reduced pressure drop $(\approx 2-7 \mathrm{psi})$ while maintaining an adequate loop time constant $(\approx 2-4$ minutes). These parameters were calculated for flowrates needed to heat the oil from $225-325^{\circ} \mathrm{C}$ from either $200-\mathrm{kW}$ or $400-\mathrm{kW}$ heat input into the system with properties averaged over the temperature range, respectively.

\section{Ethylene - Glycol Heat Exchanger}

An oil-to-glycol heat exchanger will act as a heat sink/heat control unit for the loop. For the first phase/shakedown testing of the loop, this heat exchanger will act as a "dummy load," which is meant to act as a heat consumer for TEDS. This heat exchanger will be installed outside the Energy System Laboratory (ESL) D100 high-bay with an ethylene glycol capable pump to remove the heat. The heat exchanger is designed by Graham Engineering Answers; it is a Heliflow shell and tube style heat exchanger with Therminol-66 running on the inside coils and a 50\% ethylene glycol-water mixture on the shell side of the heat exchanger, as shown in Figure 4. The Graham Heliflow heat exchanger can remove 280-kW (e.g., 960,000 BTU/h). 


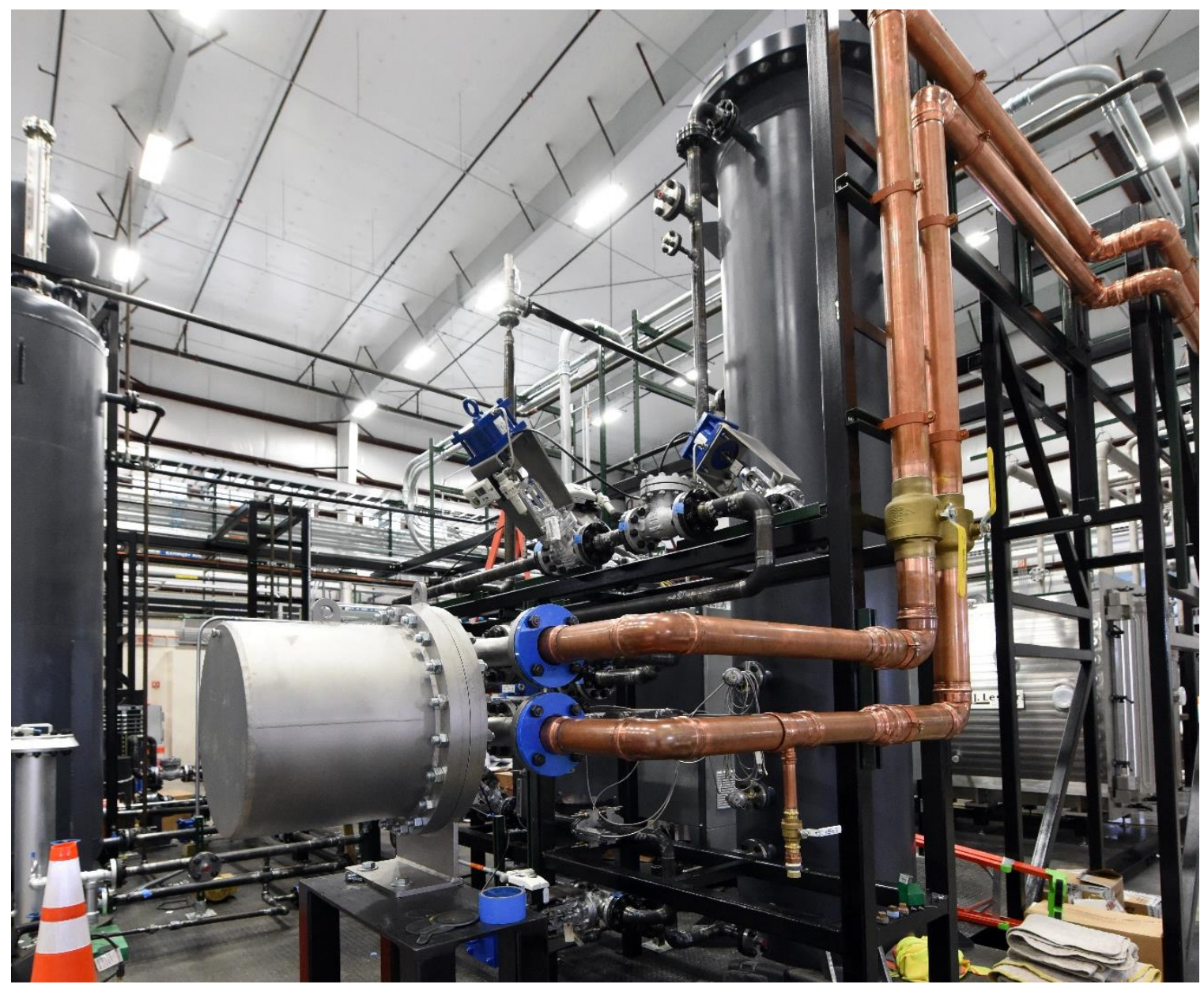

Figure 4. Graham Heliflow heat exchanger installed on the TEDS.

\section{Expansion Tank}

A 300-gallon expansion tank was purchased from Chromalox and will be used to accommodate Therminol-66 expansion to function as a knock-out tank to remove dissolved gases (such as air) from the oil and maintain system pressure. This tank is located at the highest elevation point in the system, which is recommended by Chromalox to be at least $15 \mathrm{ft}$. from the bottom of the tank to the pump. This location will provide an adequate net positive suction head on the suction side of the pump. The tank is equipped with a nitrogen and back pressure regulator.

\section{Storage Tank}

The oil is stored in two unpressurized 500-gallon tanks. These tanks are used as a reservoir for any oil vented from high points in the piping and components. The system will be filled from and drained to these tanks. This item was procured from Chromalox with additional details available in [8].

\section{Thermal Energy Storage System}

The Thermal Energy Storage (TES) system used in TEDS is a single packed-bed thermocline tank with 1/8-in. diameter $\mathrm{Al}_{2} \mathrm{O}_{3}$ (alumina) beads as the filler material. The tank has a height of $14.5 \mathrm{ft}$. with an outer diameter of 36 in. The tank walls are 0.5 in. thick. The tank will be an ASME designed and certified Section 8 Division 1 vessel that is constructed out of carbon steel and has a pressure rating of 100 psi. Inside the tank, an upper and lower plenum allows for sufficient mixing of the oil before traveling through the packed pebble bed. These plenums are formed by flow distribution plates located at the top and bottom of 
the tank. These plates will also prevent the alumina beads from leaving the tank with the lower flow distribution plate supporting the weight of the alumina beads. Dimensions of the thermocline tank are shown in Figure 5.

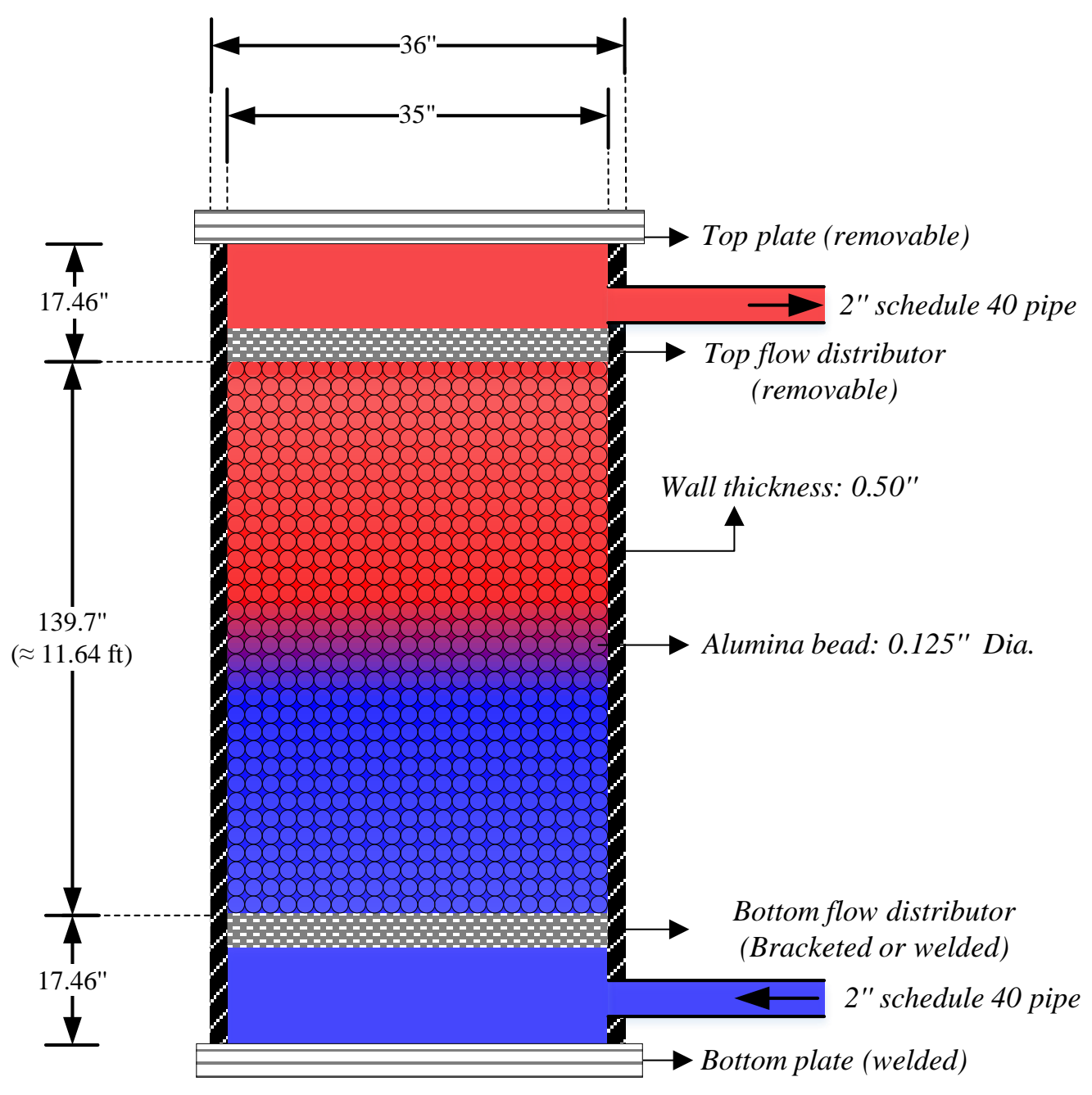

Figure 5. Thermocline tank dimensions.

The thermocline tank will be capable of operating in either a charging or discharging mode. During charging mode, the tank will behave as a heat sink. Ball valve (BV)-006, globe valve (GBV)-202, and GBV-203 will be closed, but GBV-201 and GBV-204 will remain open. This will allow the hot oil to transfer its heat to the alumina beads until an equilibrium temperature has been reached and the system has reached its storage capacity. On the other hand, during discharging mode, the TES will act as a heat source by opening valves GBV-202 and GBV-203, closing GBV-201 and GBV-204, and having BV-006 being either opened or closed. The cooler oil flow from the bottom to the top of the tank until the outlet temperature at the top of the tank reaches $325^{\circ} \mathrm{C}$. It then starts to decrease until a cutoff temperature is reached. This cutoff temperature will vary based on testing performed with the TES. 


\section{MODEL OVERVIEW}

Complementing the experimental work, component modeling, and nodalization are summarized in this section. The models were developed in the Modelica language and made to be compatible with the existing suite of process models within the IES program. The models were developed to a level of fidelity sufficient to demonstrate control algorithms, process level flows, transients, and temperature profiles for various components from a process modeling perspective while still allowing for day-long simulations to be completed in a matter of minutes. Computational fluid dynamics (CFD) and thermal stress analysis were conducted using STAR CCM+ and Abaqus, but are not part of the transient process model development. Full details on the model development can be found in a previous Frick et al. report [9]. Modeling efforts described in this section were utilized to help inform the experimental design and operation prior to initial startup.

\subsection{Thermocline}

A major initial component of TEDS is the single-tank packed-bed thermocline system. This TES component can store up to $200-\mathrm{kW}$ of thermal energy. A thermocline storage system stores heat via hot and cold fluid separated by a thin thermocline region that arises due a density differential in the fluid. Assuming low mixing via internal flow characteristics and structural design, this thermocline region can be kept relatively small in comparison with the size of the tank. Additionally, large buoyancy changes and low internal thermal conductivity are also extremely useful in maintaining small relative thermocline thickness.

To increase the cost-effective nature of these designs, it is common to fill the tank with a low-cost filler material, such as concrete or quartzite. These filler materials are inexpensive, have high density, and high thermal conductivity. By using such material, a reduction in the amount of high-cost thermal fluid can be achieved, thereby increasing the economic competitiveness of such designs.

The thermocline system was modeled using a modified set of Schumann equations that were originally introduced in 1927 [10]. The equation set governs energy conservation of fluid flow through porous media. This equation set has been widely adopted in the analysis of thermocline storage tanks. The modified equations adopted a new version of the convective heat transfer coefficient to incorporate low and no flow conditions from Gunn in 1978 [11]. Additionally, a conductive heat transfer term was added for the heat conduction through the walls of the tank. Self-degradation of the thermocline in the axial direction is neglected due to low relative values during standard operation. This is a known limit of the model during times of no flow. System nodalization is shown in Figure 6. During charging mode, the flow runs from the hot side to the cold side; in discharge mode, it runs in the opposite direction. The boundary conditions of each node depends on the direction of the flow and the advection of the previous values of the nodes. For example, if the thermocline is operating in discharge mode, node $\mathrm{N}-1$ will receive boundary values from node $\mathrm{N}-2$. In charging mode, node $\mathrm{N}-1$ will use boundary conditions from node $\mathrm{N}$. 


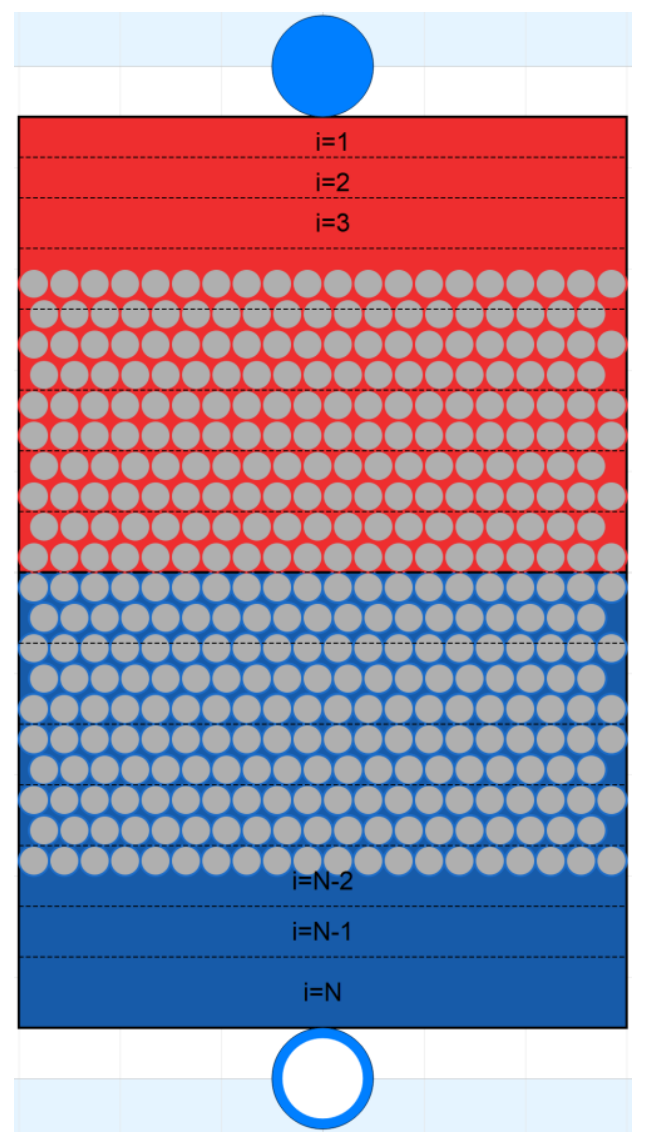

Figure 6. Nodal representation of thermocline model from Modelica.

In addition to the axial representation of heat distribution through a packed-bed porous medium, radial temperature losses exist through the tank walls and insulation to the ambient area surrounding the tank. The simulation accounts for this heat loss in each nodal fluid profile. Heat losses are calculated using Fourier's law of heat conduction $q^{\prime \prime}=-k \frac{d T}{d x}$ using built-in Modelica conduction models and propagated to the thermocline governing equations at each axial node.

\subsection{Chromalox Heater}

The Chromalox heater is modeled as a multi-node pipe with the heat input equally distributed throughout, as shown in Figure 7. The heater operates to maintain the temperature at "sensor_T1" at some nominal setpoint. This is achieved thanks to a proportional integral derivative (PID) controller that ensures an equal heat input into each segment of the Chromalox heater. The heater is bounded to a maximum heater input according to vendor specifications. Regarding pressure loss terms, heater mass flow is assumed to be fully developed and capable of operating in either the laminar or turbulent region depending on the Reynolds number of the pipe. Heat transfer into the pipe is assumed to be ideal since the heating elements are in direct contact with the fluid. 


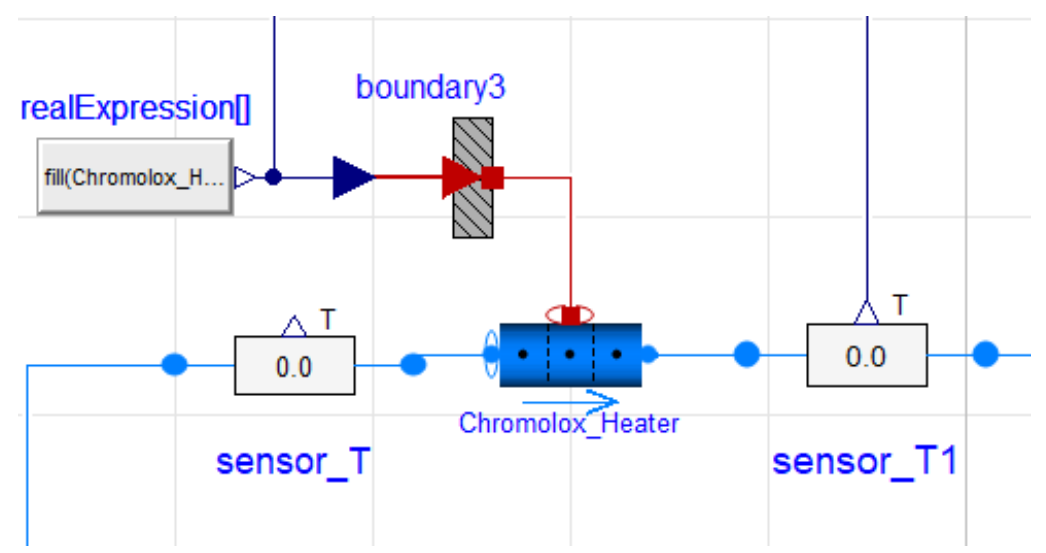

Figure 7. Chromalox heater.

\subsection{Ethylene Glycol Heat Exchanger}

The ethylene glycol heat exchanger was modeled using the TRANSFORM heat exchanger model as a shell and tube heat exchanger with Therminol-66 operating on the shell side of the heat exchanger and ethylene glycol on the tube side. Ethylene glycol flow rate flow operates via a flow control valve that oscillates to ensure a specified shell side Therminol-66 setpoint temperature is met. Heat transfer on the tube side is modeled via the Dittus-Boelter correlation, whereas on the shell side, a single phase two-region heat transfer mode is used along with correction factors adjusted to meet predetermined heat transfer characteristics. The heat exchanger setup is depicted in Figure 8.

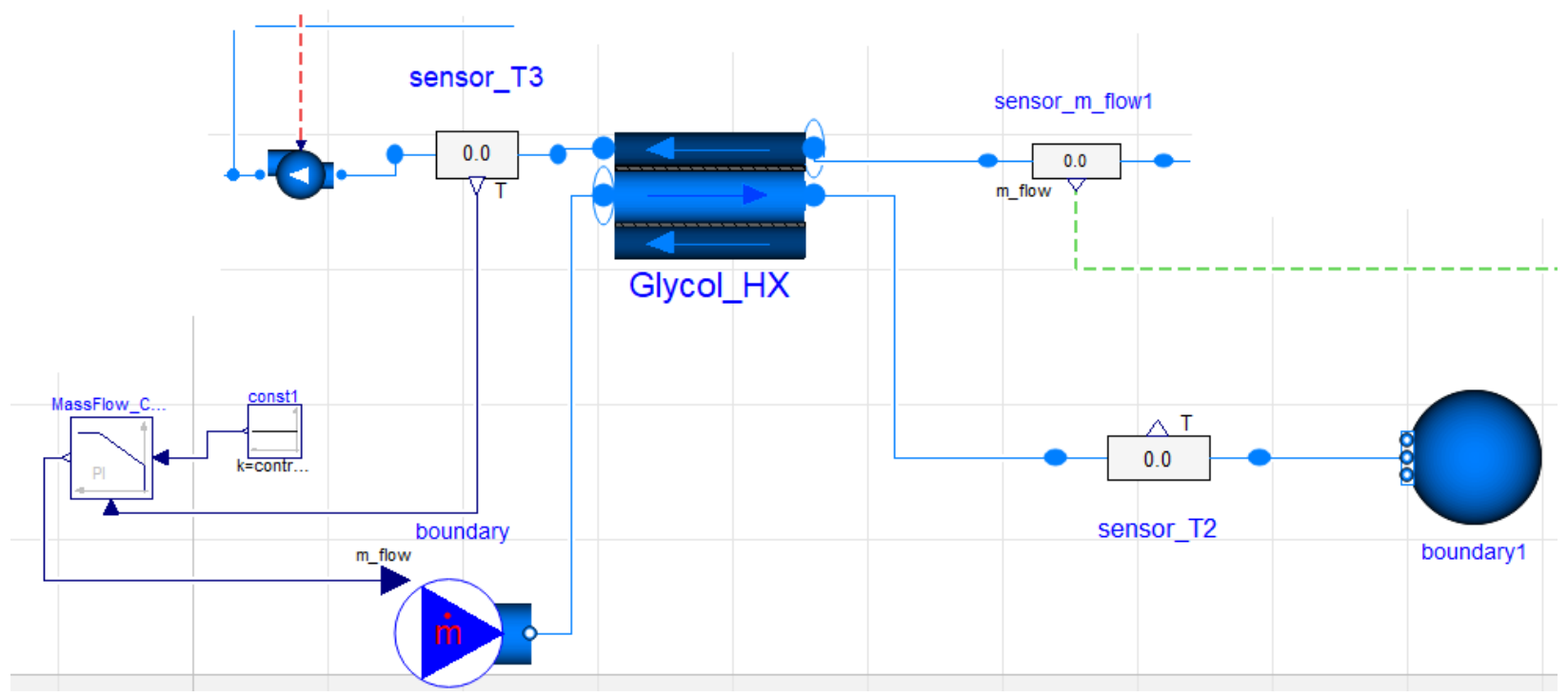

Figure 8. Ethylene glycol heat exchanger.

\subsection{Insulation Thickness}

Assuming an infinitely wide tank, perfect insulation, or ambient temperatures equivalent to thermocline tank temperatures, heat loss through the walls of the tank would not be a concern. Unfortunately, such conditions do not exist, and heat losses are an important concern for thermal storage units. They are of even higher consequence in structures that present a high relative surface area compared to the internal volume. Due to size constraints within the experimental lab, this is an omnipresent reality of the TEDS thermocline tank. Commercial entities that use thermocline tanks for chilled water storage have large diameters relative 
to system height and presents with relatively low thermal losses. However, the area to volume ratio of TEDS, as well as the temperature difference between the internal fluid and ambient surroundings, are relatively large. Therefore, the calculation of the necessary insulation thickness is a trade-off between cost, physical space to place the insulation, and heat losses. To determine relative heat losses that are acceptable, a simulation of temperature drop-off over a two-day period of inactivity was conducted. Results are presented in Figure 9.

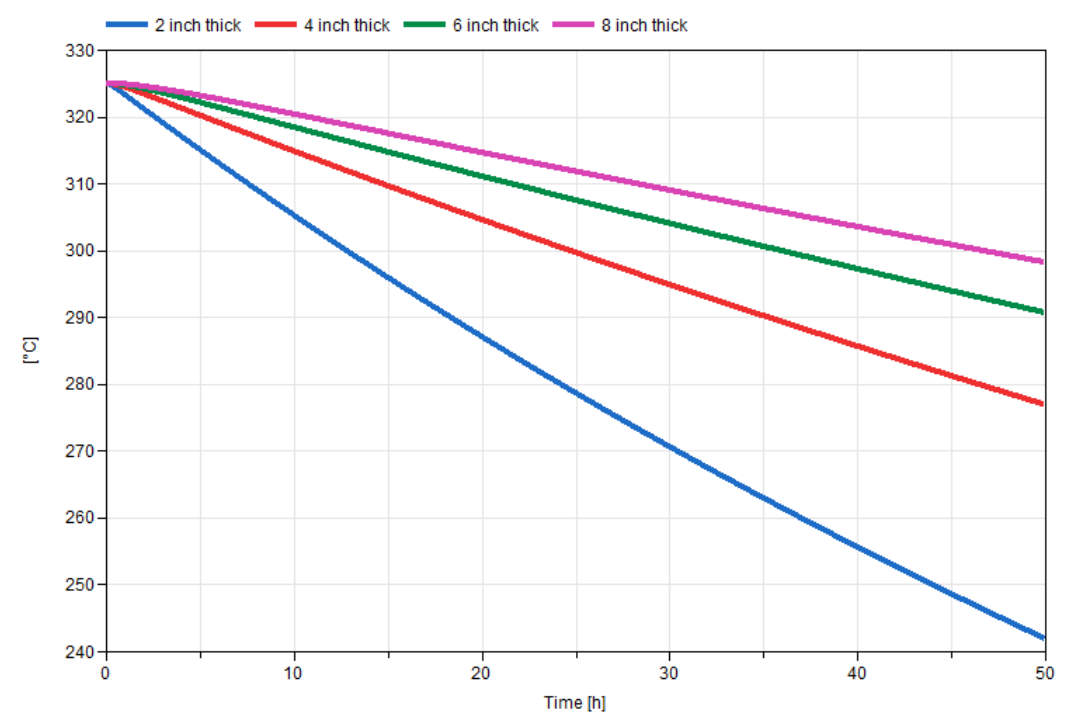

Figure 9. Thermocline temperatures with varying levels of insulation.

The simulation assumes an initial thermocline temperature of $325^{\circ} \mathrm{C}$, which is consistent with a fully charged thermocline system. Flow is assumed to be stagnant. The simulation considers FOAMGLAS® ONE insulation thicknesses of 2 in., 4 in., 6 in., and 8 in.; 8 in. is the upper bound of physical space surrounding the thermocline in which insulation could be placed. For the 2-in.-thick insulation, ambient heat losses would equate to $\sim 80^{\circ} \mathrm{C}$ drop in average tank temperature over two days. Four-in.-thick insulation equates to a $47^{\circ} \mathrm{C}$ drop in the average temperature, while a six-in.-thick layer equated to a $33^{\circ} \mathrm{C}$ heat loss. Eight-in.-thick insulation was only modestly better at a $27^{\circ} \mathrm{C}$ drop over two days. From this simulation, it was determined that a six-in.-thick layer of insulation offers the best trade-off in terms of effective storage of heat, while adequately fitting in the space surrounding the tank. 


\section{TEDS CONTROL SYSTEMS}

In addition to the components discussed in the previous section, a series of valves, sensors, and control algorithms is required to ensure all operational modes are possible while maintaining component properties within acceptable limits. A full operational schematic of TEDS in Modelica is provided in Figure 10 and Figure 11. This section provides an in-depth description of the operational control schemes utilized in TEDS. For purposes of initial deployment, it is assumed the energy system consists of a heat generator, a thermal storage unit, and a heat sink that could be either a standard balance of plant (BOP) or ancillary process.

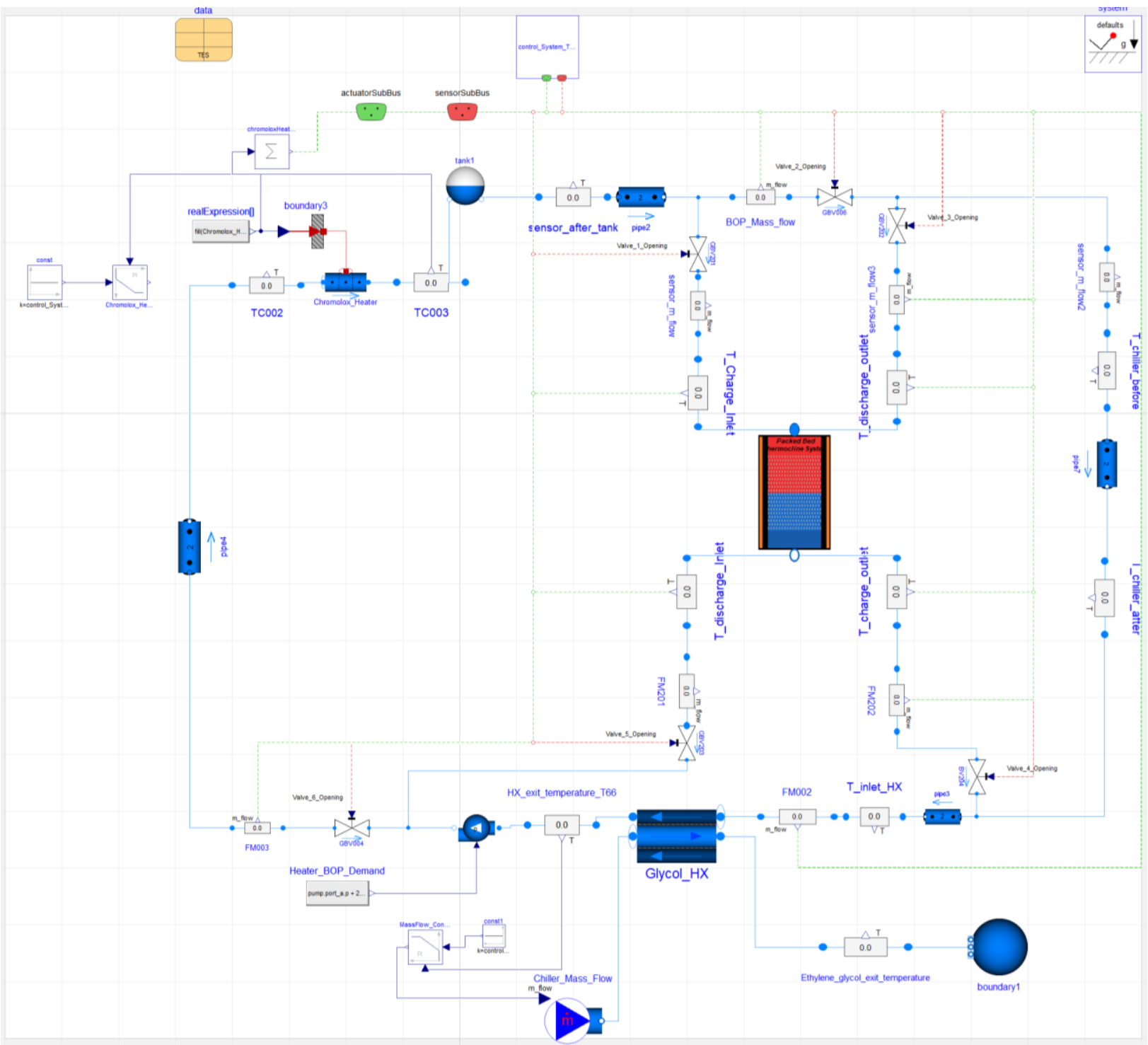

Figure 10. Modelica TEDS model. 


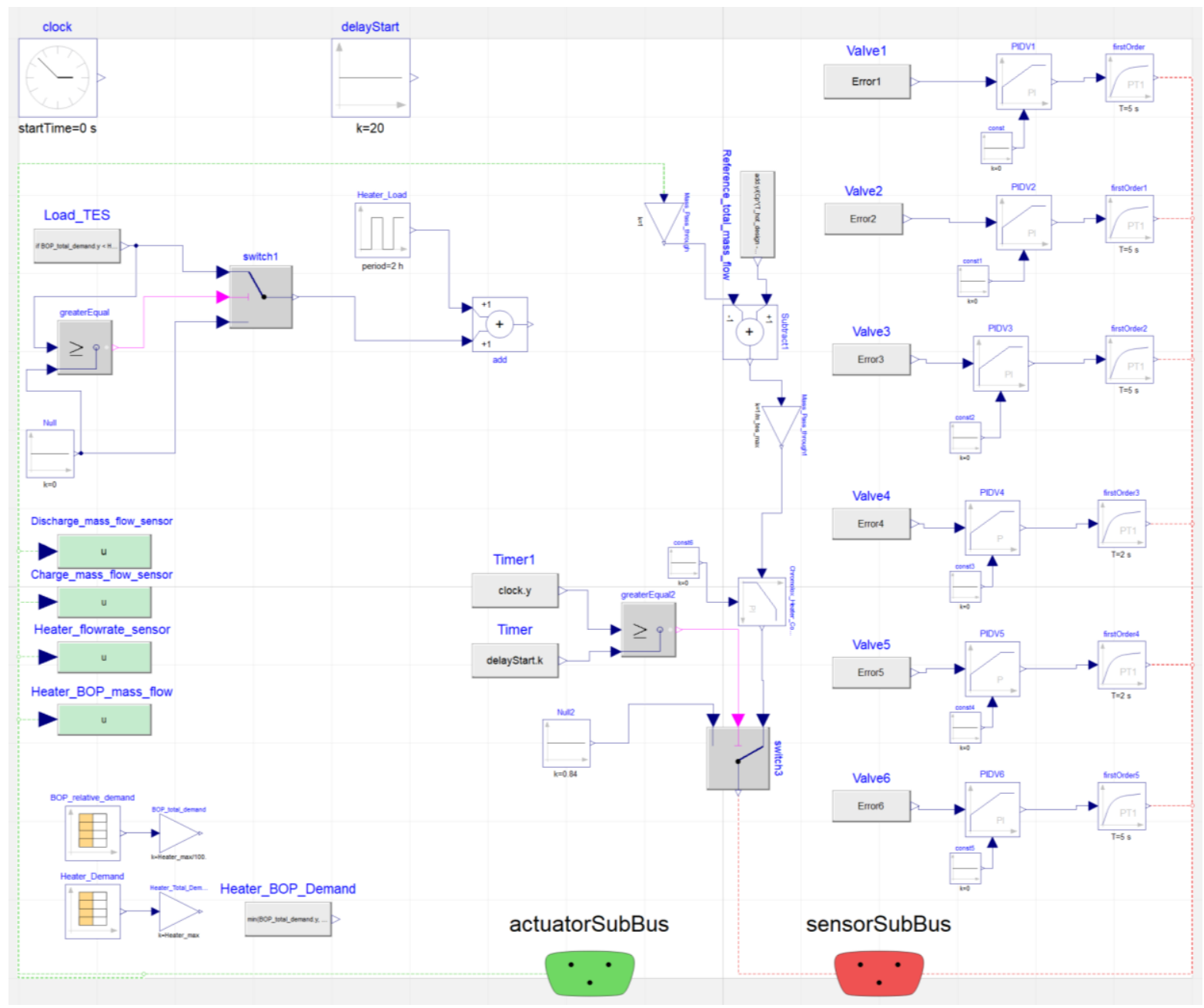

Figure 11. Pictorial layer of control algorithm.

\subsection{Operational Modes}

The TEDS dynamic flexibility stems from its potential to operate in several different modes. However, with increased flexibility comes increased control complexity. To control the system, all foreseeable operating modes need to be accommodated with a single cohesive control strategy. In the initial deployment configuration, there are five possible operating modes each involving the thermal storage unit, as depicted in Table 1.

Table 1. Foreseeable operational modes.

\begin{tabular}{|l|l|l|l|}
\hline Mode & Heat Source to Load & (Heat Source to Thermocline) & Charging $\begin{array}{c}\text { Discharging } \\
\text { (Thermocline to Load) }\end{array}$ \\
\hline 1 & Yes & No & No \\
\hline 2 & No & Yes & No \\
\hline 3 & No & No & Yes \\
\hline 4 & Yes & Yes & No \\
\hline 5 & Yes & No & Yes \\
\hline
\end{tabular}


Mode 1 simulates the heat generation source operating in standard operational mode with no energy storage. This mode is akin to currently operating generators accommodating a standard load-following mode. Mode 2 simulates a full-charging scenario where the thermal generator is sending all its heat to the thermal storage unit. Mode 3 simulates a full discharge scenario: the thermal generator is turned off and the thermal storage unit is the sole unit providing heat to the BOP or ancillary process. Mode 4 is a combination of modes 1 and 2: the thermal generator is providing a portion of its heat to thermal storage and a portion to the heat load. Typically, this operational unit provides heat to the load first and then dumps excess heat into the thermal storage unit for use later. Mode 5 involves a combination of Modes 1 and 3: both the thermal generator and thermal storage tank are providing heat to the load. This operational modality would be common in an area that utilizes a large amount of variable renewable energy (i.e., such as areas in the Midwest that heavily rely on wind energy). To appropriately accommodate these operating modes, a combination of five valves are needed. Table 2 indicates each valve's position for each mode.

Table 2. Valve positioning in TEDS.

\begin{tabular}{|l|l|l|l|l|l|l|}
\hline \multicolumn{1}{|c|}{ Name } & \multicolumn{1}{|c|}{ Valve } & $\begin{array}{c}\text { Position } \\
\text { (Mode 1) }\end{array}$ & $\begin{array}{c}\text { Position } \\
\text { (Mode 2) }\end{array}$ & \multicolumn{1}{|c|}{$\begin{array}{c}\text { Position } \\
\text { (Mode 3) }\end{array}$} & $\begin{array}{c}\text { Position } \\
\text { (Mode 4) }\end{array}$ & \multicolumn{1}{c|}{$\begin{array}{c}\text { Position } \\
\text { (Mode 5) }\end{array}$} \\
\hline GBV-201 & 1 & Closed & Open & Closed & Open & Closed \\
\hline GBV-006 & 2 & Open & Closed & Closed & Open & Open \\
\hline GBV-202 & 3 & Closed & Closed & Open & Closed & Open \\
\hline BV-204 & 4 & Closed & Open & Closed & Open & Closed \\
\hline GBV-203 & 5 & Closed & Closed & Open & Closed & Open \\
\hline
\end{tabular}

Note: Six valves appear in Figure 10 and Figure 11. However, GBV-004 (i.e., Valve 6) is an anticipated valve for future operations and remains fully open through all presented TEDS testing modalities.

Four of the five valves are strictly required to be fully controllable GBVs, while two can operate as BVs. In practice, the experimental team has made four of these valves GBVs in anticipation of future operational modalities.

\subsection{Supervisory Control Scheme}

While the ability exists to impose bespoke demand signals to each individual system component, it is more relevant to consider markets scenarios that would impose each of the modes designed for the system. To incorporate this need, two separate market demand inputs are available for use: heater power level and overall system demand. IESs that include a thermal storage unit typically have the objective function defined to maximize profits or meet overall system demand depending on the type of market they operate in. In regulated markets, IESs are designed to meet overall system demand at as low a cost as possible. In de-regulated markets, the goal is to maximize system profits. In either scenario, it is advantageous to operate the thermal generator, particularly if it is nuclear, at full capacity and bypass excess steam into storage during times of low electricity pricing or low grid demand and to discharge the TES unit during high prices or high demand. However, for purposes of refueling, maintenance, or excessively low demand/pricing, there may be times when the thermal generator will need to power down separately from the thermal storage unit. Therefore, two separate signals for overall demand and thermal generator power are available.

To determine the thermal storage demand, the following control logic is used:

$$
\operatorname{Load}_{T E S}(t)=\operatorname{Total}_{\text {Demand }}(t)-\operatorname{Heater}_{\text {Demand }}(t)
$$


where:

$$
\begin{gathered}
\operatorname{Total}_{\text {Demand }}(t)=\text { Market }_{\text {Demand }}(t) \\
\operatorname{Heater}_{\text {Demand }}(t)=\text { Generator }_{\text {Decision }}(t)
\end{gathered}
$$

If $\operatorname{Load}_{T E S}(t)<0$ then excess capacity is to be sent to the thermal storage unit to be stored If $\operatorname{Load}_{T E S}(t)>0$ then the thermal storage unit will begin discharge operation.

\subsection{Control Strategies}

To properly control the system for each mode, a state variable needs to be communicated to the centralized control unit. This is accomplished via mass, temperature, and flow sensors installed throughout the loop. The placement of these sensors is illustrated in Figure 10. Using these sensors, a control action can be taken in accordance with the desired overall system action. All controllers operate on a proportional integral (PI) controller rather than a proportional integral derivative (PID) controller or simply a proportional $(\mathrm{P})$ control algorithm.

Valve 1: GBV-201 oscillates to meet a charging mass flow rate setpoint that is discerned off a reference load as shown, using flow meter (FM)-202:

$$
\begin{gathered}
\dot{m}_{\text {chargingDemand }}=\frac{\left|\operatorname{Load}_{T E S}\right|}{c_{\text {pavg }}\left(T_{\text {HotSP }}-T_{\text {ColdSP }}\right)} \text { ifLoad }_{T E S}<0 \text {, else } 0 \\
\text { Error }_{1}=\frac{\dot{m}_{\text {chargingDemand }}-F M_{202}}{\dot{m}_{\text {chargingMax }}}
\end{gathered}
$$

Valve 2: GBV-006 oscillates to match a simulated BOP demand via a referred flow rate signal from FM-003 and FM-202.

$$
\begin{gathered}
\dot{m}_{\text {BOPDemand }}=\frac{B O P_{\text {Demand }}}{c_{\text {pavg }}\left(T_{\text {HotSP }}-T_{\text {ColdSP }}\right)} \\
\text { Error }_{2}=\frac{\dot{m}_{\text {BOPDemand }}-\left(F M_{003}-F M_{202}\right)}{\dot{m}_{\text {BOPMax }}}
\end{gathered}
$$

Valve 3: GBV-202 maneuvers to match the simulated discharge demand via a signal from FM-201.

$$
\begin{gathered}
\dot{m}_{\text {dischargeDemand }}=\frac{\operatorname{Load}_{T E S}}{c_{\text {pavg }}\left(T_{\text {HotSP }}-T_{\text {ColdSP }}\right)} \text { if Load }_{\text {TES }}>0 \text {, else } 0 \\
\text { Error }_{3}=\frac{\dot{m}_{\text {dischargeDemand }}-F M_{201}}{\dot{m}_{\text {dischargeMax }}}
\end{gathered}
$$

Valve 4: BV-204 operates on an interlock system with GBV-201. The interlock system operates with a five-second opening delay to ensure the charging and discharge lines cannot both be open simultaneously. If the charging demand goes to zero, BV-204 will move to the fully closed position blocking all flow in the charge line. If demand is positive, BV-204 will wait five seconds, allowing time for the discharge line to fully close, and then it will move to the fully open position. 
Valve 5: GBV-203 operates in the same manner as Valve 4, but for the discharge line, which is on an interlock system with GBV-202. In the event discharge demand is greater than zero, GBV-202 will begin to open, while GBV-203 remains closed for five seconds past when GBV-203 begins to open to ensure the charging line is fully closed prior to discharge operation.

Chromalox Heater: The Chromalox heater input is controlled to match thermocouple (TC)-003 with a reference heater exit temperature while staying below the maximum heater input of $200-\mathrm{kW}$. It is assumed that this heat input is homogeneous along the length of the heater and that the heater input can be controlled continuously.

$$
\text { Error }_{\text {Heater }}=T_{\text {Setpoint }}-T C_{003}
$$

If the temperature from TC-003 is below the temperature setpoint, the heater input will increase. Conversely, if TC-003 is higher than the setpoint temperature, the heater input will reduce.

Chiller: The ethylene glycol chiller modulates coolant mass flow to maintain Therminol-66 exit temperature at a setpoint temperature based on the signal coming from TC-005.

$$
\text { Error }_{\text {chiller }}=T C_{005}-T_{\text {Setpoint }}
$$

If the setpoint temperature is cooler than TC-005, then coolant mass flow will increase causing more heat transfer from the Therminol-66; thus, decreasing outlet temperature. Alternatively, if the setpoint temperature is higher than TC-005, then the coolant mass flow decreases, which lowers the amount of heat transfer across the tubes, and the Therminol-66 exit temperature rises. In addition to this control methodology, a minimum mass flow constraint was placed on coolant flow to ensure coolant boiling does not occur. This constraint means that during times of low Therminol-66 flow or low inlet temperature on the Therminol-66 side, a decrease in exit temperature will occur despite the error signal signaling to the lower mass flow rate. Construction of a bypass line on the Therminol-66 side is in development to eliminate this need and allow the minimum flow rate requirement to be eliminated.

Pump: The TEDS pump speed is controlled by a VFD to ensure a constant discharge pressure. Under normal operation, this guarantees a sufficient driving force for the system valving configuration to operate in all foreseeable modes. Furthermore, if all valves in the system close, this ensures that a system overpressurization does not occur as the pump is operating to maintain a set exit pressure rather than a set mass flow rate.

\subsection{Shakedown Testing}

To illustrate the different operational modes for TEDS a test case was designed to run TEDS in each mode. For this simulation, operational parameters are available in Table 3. Simulation results are available in Figure 12, Figure 13, and Figure 14. Since the Chromalox heater has a maximum output capacity of $200 \mathrm{~kW}$ it is necessary to leave some margin under standard operation to allow for a power demand increase from the minimum flow rate condition mentioned earlier. Therefore, for this test, a $175 \mathrm{~kW}$ output is nominal full power. Once a bypass line is installed in the TEDS system this requirement will be eliminated. 
Table 3. TEDS operational parameters.

\begin{tabular}{|l|l|}
\hline \multicolumn{1}{|c|}{ Parameter } & \multicolumn{1}{c|}{ Value } \\
\hline Fluid Material & Therminol-66 \\
\hline Filler Material & alumina \\
\hline Wall Material & stainless steel 304 \\
\hline Insulation Material & FOAMGLAS® ONE \\
\hline Porosity & 0.5 \\
\hline Filler Diameter & $0.00317 \mathrm{~m}(1 / 8 \mathrm{in})$. \\
\hline Tank Height & $4.435 \mathrm{~m}$ \\
\hline Tank Radius & $0.438 \mathrm{~m}$ \\
\hline Ambient Temperature & $20^{\circ} \mathrm{C}$ \\
\hline Nodes & 200 \\
\hline Wall Thickness & $0.019 \mathrm{~m}$ \\
\hline Insulation Thickness & $0.153 \mathrm{~m}(6$ in. $)$ \\
\hline Charge Incoming Temperature & $325^{\circ} \mathrm{C}$ \\
\hline Discharge Incoming Temperature & $225^{\circ} \mathrm{C}$ \\
\hline Maximum Heater Power & $200-\mathrm{kW}$ \\
\hline Nominal Full Heater Output & $175-\mathrm{kW}$ \\
\hline
\end{tabular}

The simulation starts with the thermal storage unit at $225^{\circ} \mathrm{C}$ as if in a fully discharged state. An initialization phase occurs for the first 300 seconds of the simulation. This initialization delay allows time for the nonlinear equations of the system to stabilize and for all the control actions from initialization to finish. Then, up until the 30-minute mark, the simulation is running in Operation Mode 1. Mode 1 does not involve the thermal storage unit and instead simulates a steady load on the thermal generator from the BOP. Nominal mass flow rate throughout the TEDS loop is $0.735 \mathrm{~kg} / \mathrm{s}$ with a nominal power input of $175-\mathrm{kW}$ from the heater, as illustrated in Figure 12, Figure 13, and Figure 14. At the 30-minute mark, total BOP demand begins to decrease while heater demand remains constant, signaling the charging operation to begin in addition to an operational switch to Mode 4.

Table 4. Mode color coordination.

\begin{tabular}{|l|l|}
\hline Mode & Color \\
\hline 1 & \\
\hline 2 & \\
\hline 3 & \\
\hline 4 & \\
\hline 5 & \\
\hline
\end{tabular}

Mode 4 begins as BV-204 is signaled to open and GBV-201 modulates to send a reference setpoint mass flow to the TES, allowing mass flow through that entire charging line. Simultaneously, GBV-006 modulates to decrease mass flow to the dummy load. During this operation mode, the chiller can maintain exit temperature of Therminol- 66 at the $225^{\circ} \mathrm{C}$ setpoint temperature, as seen in Figure 13. However, as the mass flow sent to the dummy load decreases, ethylene glycol mass flow decreases, thus increasing the shell side exit temperature. After 30 minutes in Mode 4, dummy demand decreases to zero, and a switch to Mode 2 occurs. 

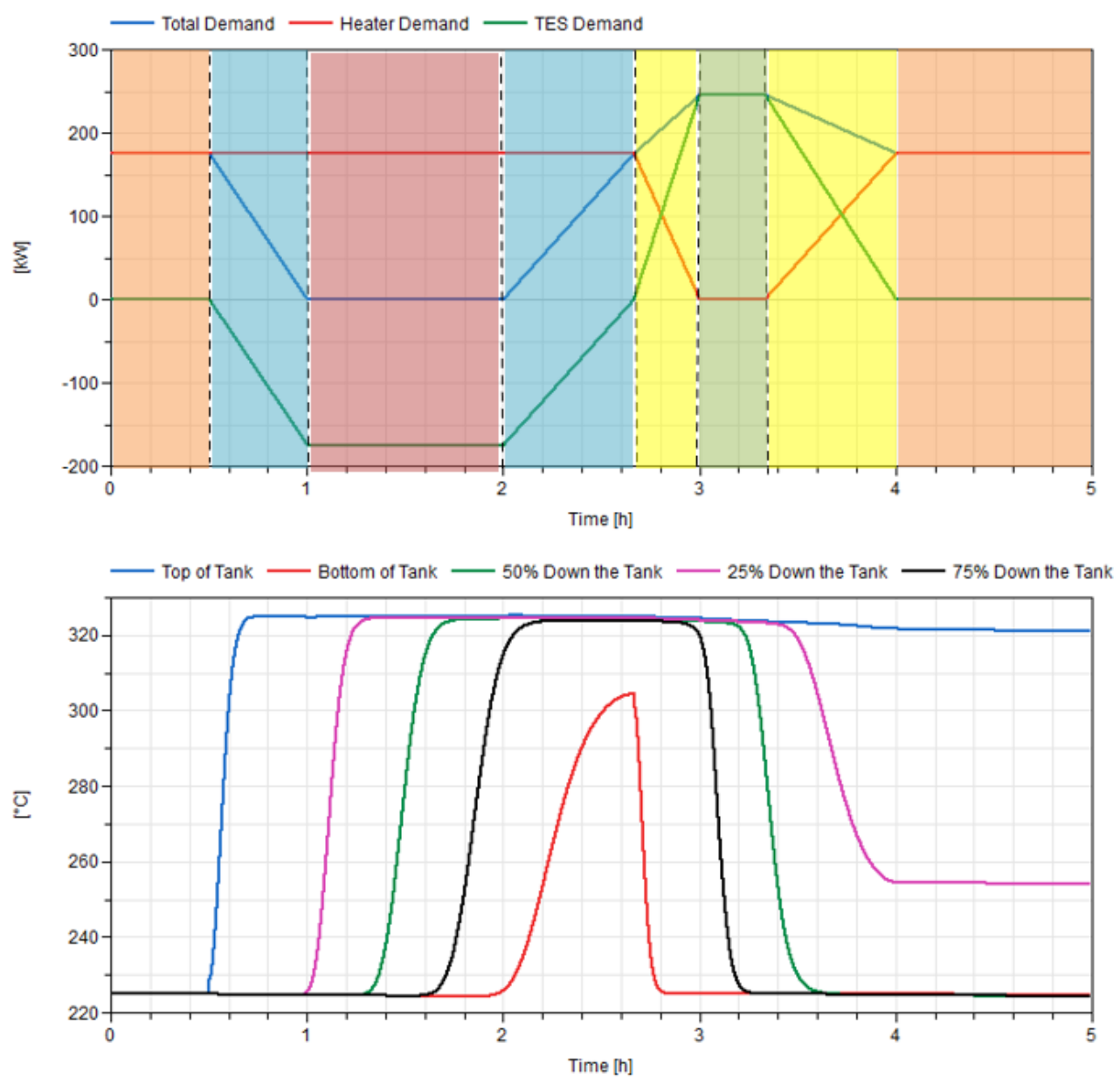

Figure 12. (Top) System demand on heater, thermocline, and total system. (Bottom) Calculated thermocline fluid temperature at varying points within the tank.

In Mode 2, there is no dummy load. Instead, all the heater heat is sent to the thermal storage unit for later use. During Mode 2 operation, the inlet temperature of the chiller is equal to the cold temperature in the thermal storage tank, this temperature is at or below the setpoint exit temperature of the chiller heat exchanger. This theoretically causes the ethylene glycol mass flow demand to fall to zero. If this were allowed, the glycol would begin to boil at $120^{\circ} \mathrm{C}$, thereby causing system fouling and degradation. Instead, a minimum mass flow rate of $0.05 \mathrm{~kg} / \mathrm{s}$ is maintained, leading to a glycol exit temperature of $\sim 83^{\circ} \mathrm{C}$. This minimum mass flow limit subsequently dropped the Therminol-66 chiller exit temperature to $217.1^{\circ} \mathrm{C}$. Because the TEDS mass flow rate remains constant, the heater begins to operate at a higher power output $(\sim 190-\mathrm{kW}$ as compared to $175-\mathrm{kW})$ to ensure an exit temperature of $325^{\circ} \mathrm{C}$. If a bypass line were utilized, this power increase would not be necessary. Mode 2 operation continues for an hour, charging the thermocline to $\sim 75 \%$ capacity based on the thermocline position seen in Figure 12.

At Hour 2, dummy demand increases, causing GBV-006 to open, moving the system back into operational Mode 4. Forty minutes into Hour 2, total demand increases above heater demand, signaling discharge operation for the thermal storage unit and an operational switch to Mode 5. As demand for the thermal storage unit moves from charging to discharge, several control actions occur. First, as $\dot{m}_{\text {chargingDemand }}$ goes to zero, BV-204 begins to close, as does GBV-201. Once BV-204 closes, a 10-second delay is instituted on GBV-203. During the delay, it cannot open nor can it be opened if BV-204 is open. This ensures an elimination of potential backflow through these lines and additionally ensures both 
charging and discharge modes cannot operate simultaneously. Once this 10-second delay is fulfilled, GBV-203 opens and GBV-202 begins modulating to allow the proper amount of mass flow through the discharge line. During this operational mode, ethylene glycol mass flow increases through the chiller to maintain the exit setpoint temperature. GBV-006 modulates as before to maintain BOP heater demand mass flow, while GBV-202 works to meet discharge mass flow requirements. The main system pump works to maintain a constant pressure difference; as such, it must increase system mass flow.
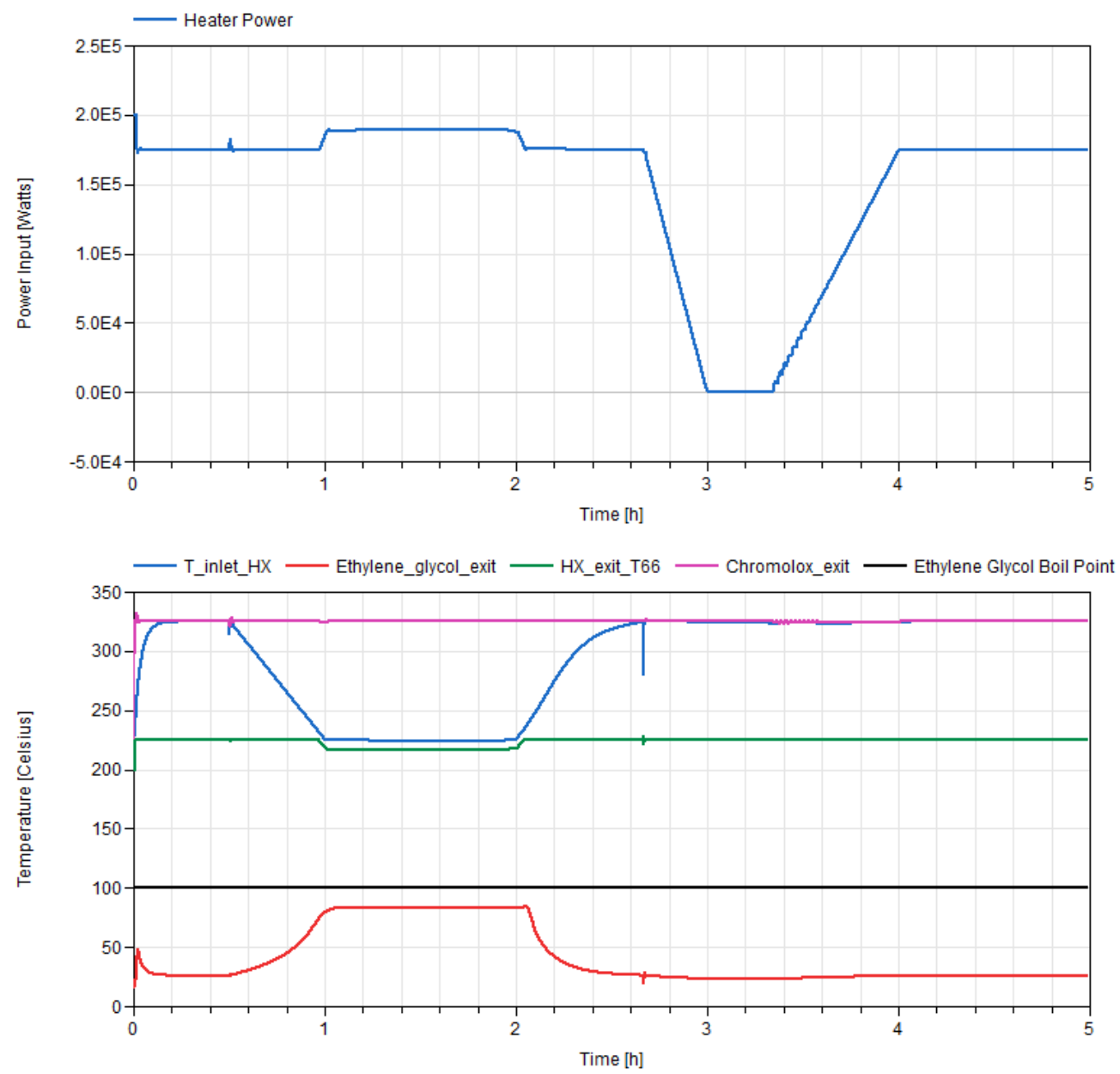

Figure 13. (Top) Chromalox heater input. (Bottom) Calculated temperatures throughout the TEDS loop.

At Hour 3, heater demand falls to zero, causing an operational switch to Mode 3. During Mode 3 operation, only the thermal storage unit is providing heat to the BOP. Heater power input falls to zero as exit temperature remains at $325^{\circ} \mathrm{C}$ during stagnant flow operation. The thermal storage unit begins to discharge more quickly as it is fulfilling the entire system demand. Twenty minutes into Hour 3 , heater demand rises above zero and the system falls back into Operational Mode 5. By the end of Hour 4, system demand and heater demand are equal. This causes the thermal storage unit to close both charging and discharge lines, and Operation Mode 1 is resumed. By the end of Hour 3, the thermal storage unit is almost entirely drained of useful energy as the discharge temperature begins to fall, as seen in Figure 12. 

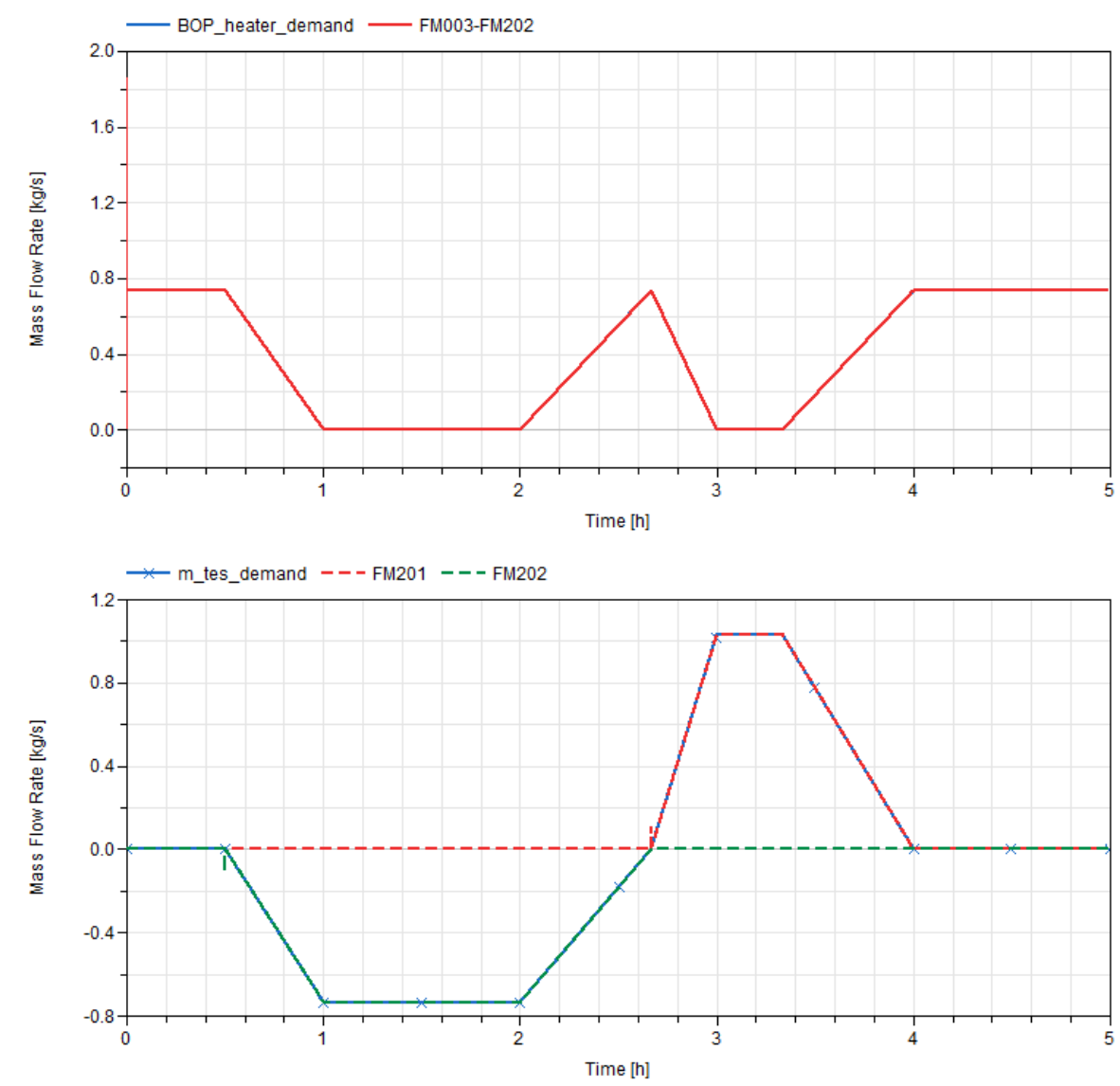

Figure 14. (Top) BOP mass flow rate. (Bottom) TES mass flow rates vs. sensor reading.

This simulation, while not entirely representative of a typical demand curve for electricity markets, illustrates the possibilities in control actions built into TEDS. Additionally, it should be noted that over the course of the simulation, heat losses occur through the thermocline tank walls and insulation at a rate of approximately $0.4^{\circ} \mathrm{C}$ per hour. Assuming a cyclic full charge and discharge cycle, this heat loss would be made up in accordance with exit temperature and temperature control mechanisms in the system since all fluid will be replaced on a routine basis. However, if a prolonged period of stagnant flow occurs, exit temperatures from the thermal storage tank will present additional challenges to the system and, at a certain point, the fluid in the thermal storage unit will cool to a point where it is no longer useful to the system. Therefore, long duration storage on the order of days or weeks is not ideal for TEDS unit operation. 


\section{VERIFICATION}

Descriptions up to this point have been focused on the experimental facility, development of models, and creation of control systems. However, to ensure confidence in the models developed, code verification must be conducted. As mentioned previously, verification is the process of checking the design of the code, confirming that the software conforms to specification, and ensuring the code is accurately representing what it was designed to represent. For TEDS, code verification will utilize a combination of static analysis, spatial discretization studies, and regression tests. A more in-depth discussion of each and its completion is provided in subsequent sections.

\subsection{Static Analysis}

Static analysis is any type of assessment of software that does not require program execution. Examples of static analysis methods include software inspection, peer review, compiling of the code, and the use of automatic static analyzers. Software inspection (or review) refers to the act of reading through the source code and other software products to find defects. Advantages of software inspections are that they are not subject to interactions between different software defects (i.e., one defect will not hide the presence of another), incomplete and nonfunctional source code can be inspected, and issues can be identified (e.g., defects, coding inefficiencies, or lack of compliance with coding standards). The rigor of the software inspection depends on the technical qualifications of the reviewer, as well as their level of independence from the software developers. Any time the code is compiled it goes through some level of static analysis. The level of rigor of the static analysis often depends on the options used during compilation.

Various software platforms have options to help with the verification process. Therefore, to properly apply verification metrics to a developed software, it is important to fully understand the capabilities of the underlying software package and its intrinsic verification capabilities. The TEDS model is developed in the commercial Modelica platform Dymola by Dassault Systems. More specifically, the models were developed in a combination of Dymola 2020, 2020x, 2021, 2021x, and 2022. Starting from the earliest release, the model has been continually updated to be consistent with the latest release of Dymola.

Since Modelica is an equation-based modeling language with a backend suite of validated DAE solvers, the verification process is reduced as the requirement of meticulously checking the transference of the continuous mathematical realm to the numerical realm is already fulfilled. This process is automatically completed by the back end of Modelica, as shown in Figure 15. The user only needs to implement the Modelica source code and the back end of Modelica solvers will translate the equation set, sort the equations into a proper solution pathway, optimize these equations, place them into the numerical realm for code generate them, and ultimately simulate them. 


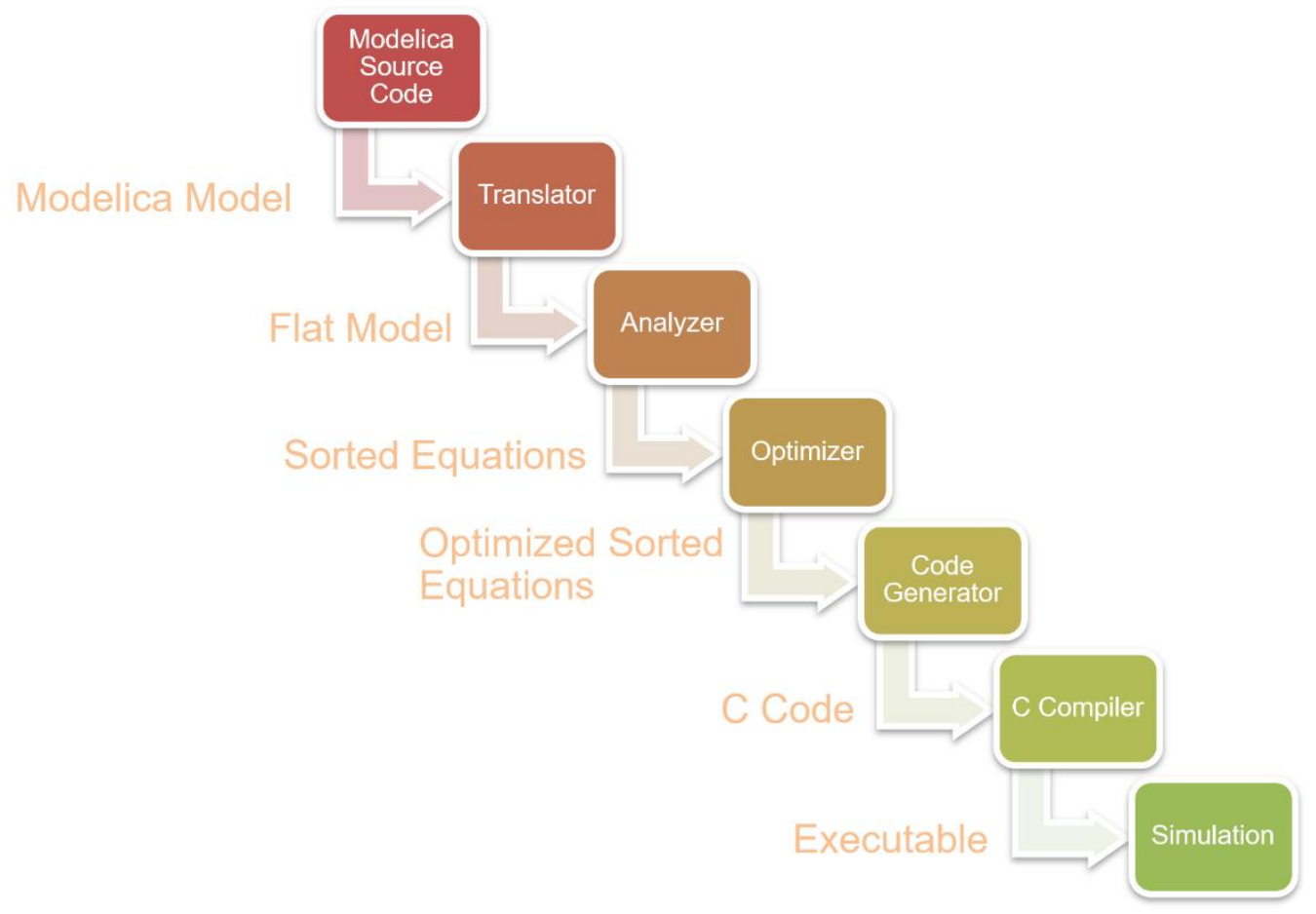

Figure 15. Compilation pathway within Modelica when a code is told to simulate. The user only needs to develop the Modelica source code.

In addition, Dymola comes with a series of automatic static analyzers capable of checking if the system is consistent, if the initial conditions are properly defined, and if any values are outside the bounds of physics with automatic warnings generated. These static analyzers are used extensively in the verification process as they provide a clear warning to the user about potential code issues.

The main static analyzer that is used is the "check" method, which is available in the Modelica user interface. This method takes the Modelica model and progresses all the way through the creation of the sorted equations inside Dymola. The goal of this "check" method is to tell the user if there are any critical errors in the code or inconsistencies in the equation set [12].

As part of the verification process, all tasks outlined in Table 5 were performed to ensure the code is operating as intended. A description of each process is as follows:

- Equation Set Check: A one-to-one comparison of the control system equation set, thermophysical property packages, and the underlying physics of the thermocline tank that were completed. The thermocline, thermophysical property packages: (e.g., Therminol-66, alumina beads, FOAMGLAS® ONE, ethylene glycol), and control systems were the only models uniquely coded for this task. All other models are base models that are separately verified in other packages.

- Boundary Condition: Boundary conditions for the ethylene glycol heat exchanger have been checked against the intended boundary condition and the appropriate values and inputs are present.

- Inputs and Outputs: An in-depth review on system inputs and outputs was conducted to ensure each of the system inputs and outputs is defined and used as intended in the code. Additionally, as part of the static analyzer "check" method in Dymola, any inputs or outputs within a code that are not connected and defined will trip a "warning message" that will be present in the log file of the code presented to the user prior to simulation. 
- Equal Number of Equations and Variables: Using the static analyzer "check" method inside Modelica, the combined TEDS model, as shown in Figure 15, was analyzed with a 200 node thermocline tank with results showing that the code has a total variable and equation set of 22,912, as shown in Figure 16.

- Errors Present According to Compilers: In the "check" method present in the Dymola graphical user interface (GUI), the number of errors present in the code are checked, whether these errors were underor over-constrained variables, whether there were incompatible variable types, or whether there were inconsistencies in the code logic. Based on the check method shown in Figure 16, there are none.

Table 5. Static testing checklist conducted on the TEDS model.

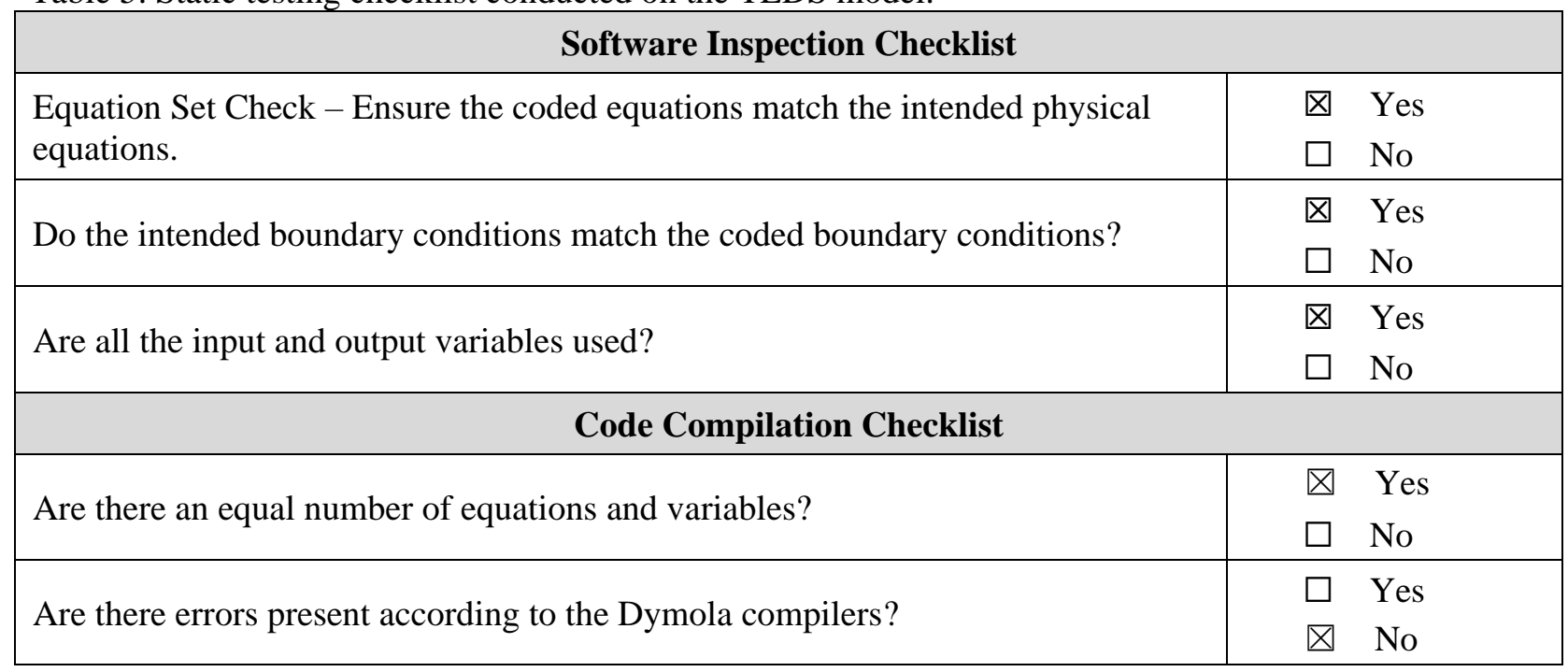

(i) Check of NHES.Systems.EnergyStorage.ThermoclineHeatStorage.Examples.TEDSloop Summerday:

(i) Note:

Your model is using an outer "systemTF" component but an inner "systemTF" component is not defined.

For simulation drag TRANSFORM.Fluid.SystemTF into your model to specify system properties.

(i) Additional warnings of this type will not be written.

(i) The model has the same number of unknowns and equations: 22912

(i) Check of NHES.Systems.EnergyStorage.ThermoclineHeatStorage.Examples.TEDSloop Summerday successful.

Figure 16. Log file generated inside Dymola 2021x describing the equation set when the "check" method is executed. 


\subsection{Regression Test}

To demonstrate the ability of the model to properly charge and discharge through hourly and daily cycling, a periodic sample was conducted. System parameters are available in Table 6. Therminol-66 is the working fluid, and the filler material is alumina beads with a total porosity of 0.6 , meaning the system is $40 \%$ alumina beads by volume. To test charging and discharging capability, an 8-hour periodic cycle was imposed on the system. The first four hours are spent discharging the system, while the next four are spent charging the system with hot Therminol-66. This is illustrated in Figure 17. Figure 18 illustrates that the bottom of the tank quickly falls in temperature as the colder fluid comes in during discharge operations and starts to move up the tank. Toward the end of the initial four hours, the top of the thermocline tank begins to decrease in temperature as the thermal gradient begins to reach the top of the tank. At this point, the thermocline would no longer be a useful source of heat. Then, at Hour 4, flow reverses and the tank begins to charge with hot fluid. As the hot fluid comes from the top, the top node of $\mathrm{i}=1$ rises back up to $325^{\circ} \mathrm{C}$ as the hot fluid passes that position and moves down the tank. Initially, the bottom of the tank remains at the nominal value of $225^{\circ} \mathrm{C}$. Towards the end of Hour 4 , the bottom of the tank begins to increase in temperature as the thermal gradient reaches the bottom of the tank, at which point the tank is almost fully charged. Filler material follows the same pattern in each node as depicted in the bottom of Figure 18. These transient simulations are then repeated over the next 50+ hours. Results do not vary despite the large ambient temperature difference since the tank is well insulated from the $0.2 \mathrm{~m}$ of fiberglass. The filler material, while being a large source of stored heat per volume, causes an exacerbation of the thermocline thickness as it conducts heat to the fluid. This can be seen at Hour 8 where Node 150 is not yet at the nominal inlet temperature, while Node 200 is already being heated. This means that the thermocline thickness has expanded to encompass $25 \%$ of the tank height. This expansion is due to the lag in time it takes for the filler to fully give up its heat as the thermocline passes by.

Table 6. Test case parameters.

\begin{tabular}{|l|l|}
\hline \multicolumn{1}{|c|}{ Parameter } & \multicolumn{1}{c|}{ Value } \\
\hline Fluid Material & Therminol-66 \\
\hline Filler Material & alumina \\
\hline Wall Material & stainless steel \\
\hline Insulation Material & fiberglass \\
\hline Porosity & 0.6 \\
\hline Tank Height & $14.6 \mathrm{~m}$ \\
\hline Tank Radius & $7.6 \mathrm{~m}$ \\
\hline Ambient Temperature & 20 Celsius \\
\hline Nodes & 200 \\
\hline Wall Thickness & $0.051 \mathrm{~m}$ \\
\hline Insulation Thickness & $0.204 \mathrm{~m}$ \\
\hline Charge Incoming Temperature & 325 Celsius \\
\hline Discharge Incoming Temperature & 225 Celsius \\
\hline
\end{tabular}




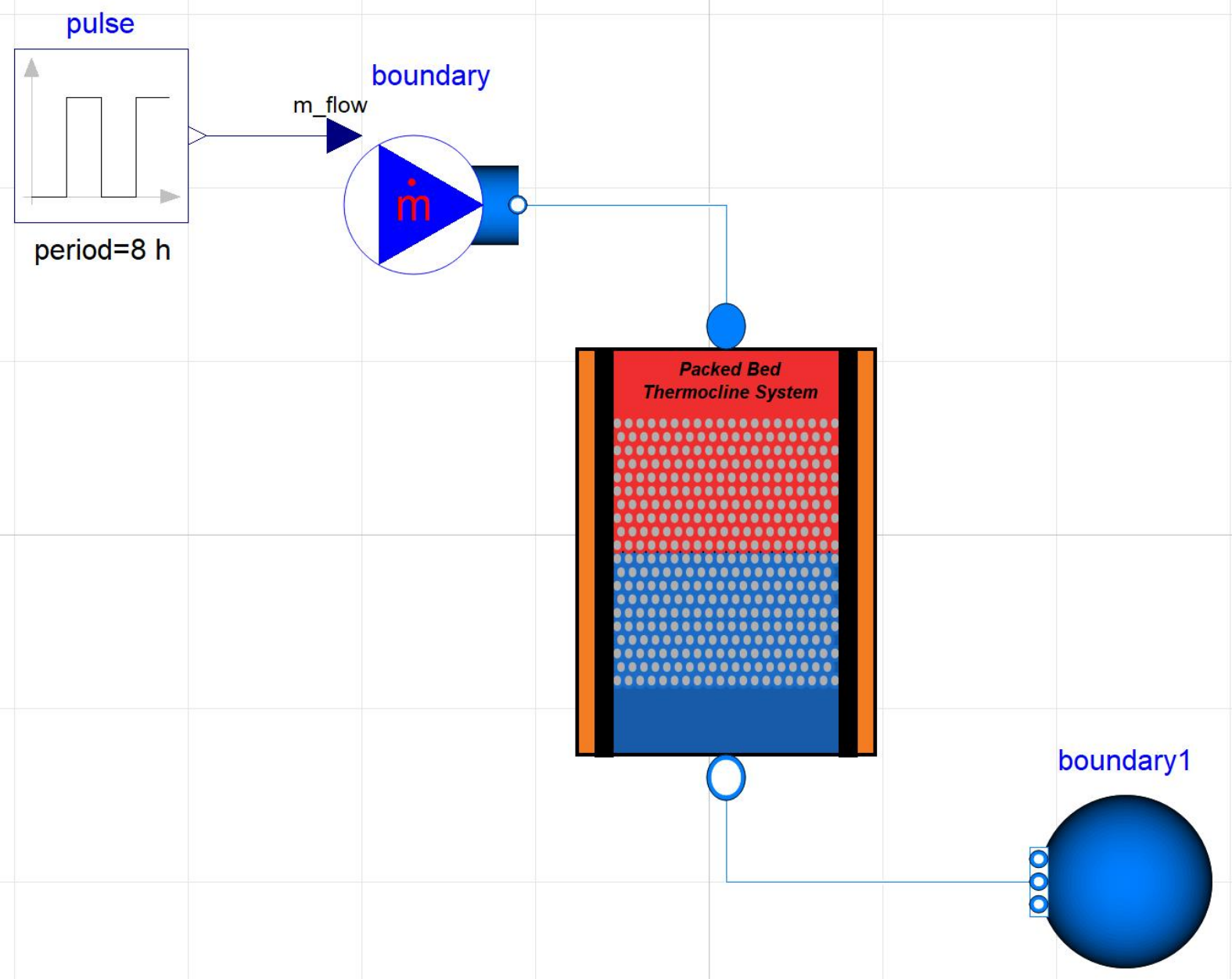

Figure 17. Periodic charging and discharging thermocline test. 

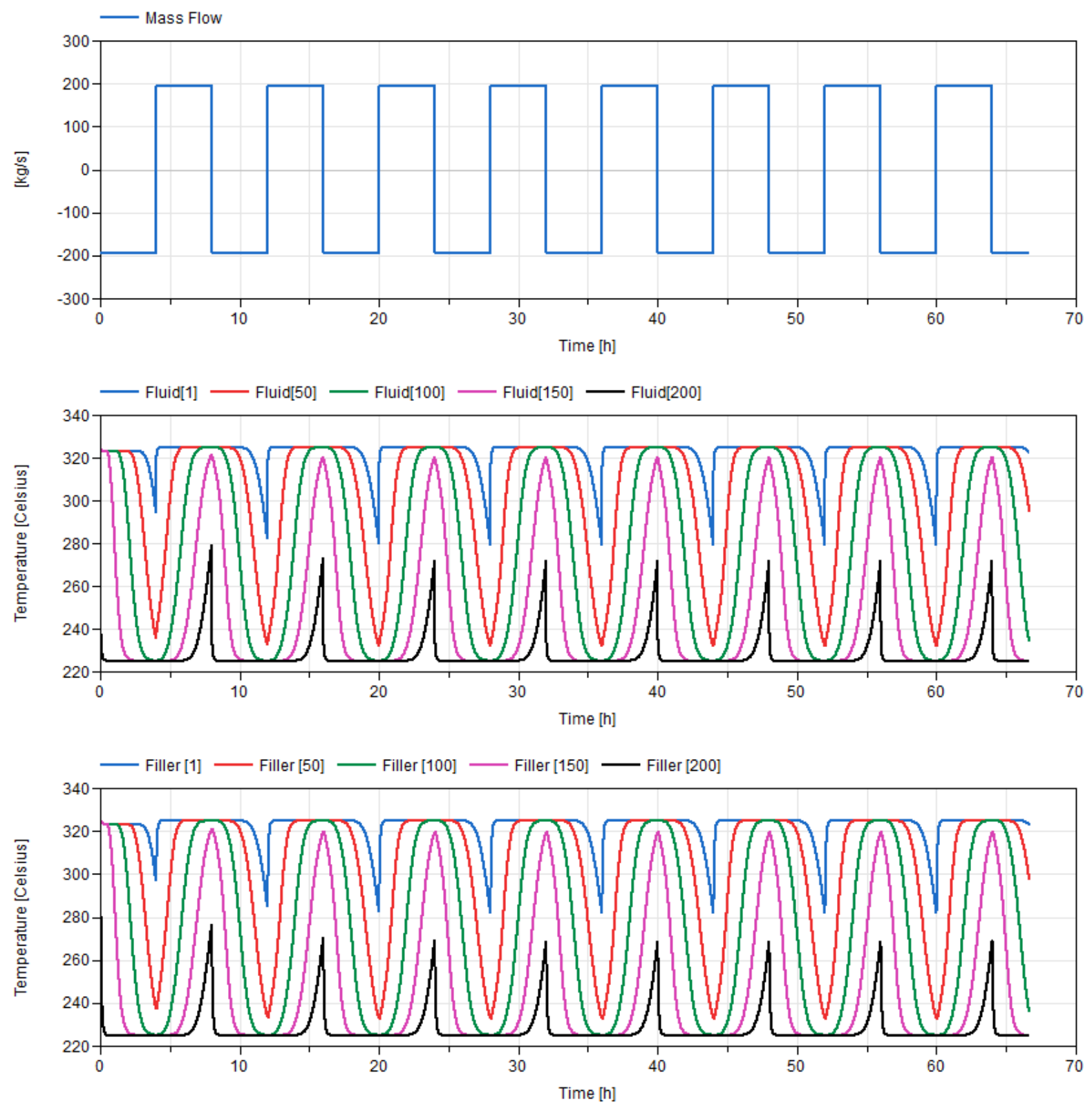

Figure 18. Fluid and filler temperature at axial locations of $i=1$ (top of tank), $i=50$ ( $25 \%$ down the tank), $\mathrm{i}=100$ (50\% down the tank), $\mathrm{i}=150$ ( $75 \%$ down the tank), and $\mathrm{i}=200$ (bottom of the tank.).

\subsection{Spatial Refinement Test}

As stated earlier in this report, the thermocline heat storage tank is the centerpiece of TEDS. Therefore, an important part of the verification process is focused on the modeling of this component behavior. A spatial refinement test has thus been conducted to estimate the discretization error and find the relevant trade-off between accuracy and computational time.

To conduct this spatial refinement test, the following methodology was followed:

1. The regression test presented in the previous section was run for different thermocline grids: a constant grid refinement factor of 2 was chosen, and simulations were run with 25, 50, 100, 200, and 400 nodes. 
2. The average temperatures at various elevations in the thermocline tank were computed (e.g., top, onequarter, middle, three-quarters, and bottom of the tank). It must be noted that when increasing the number of nodes, this average temperature calculation implies time- and node-averaging to ensure the coherence of the comparison. For instance, to compare the temperature at the top of the tank, the time-average temperature of Node 1 of the 25-node simulation will be compared to the average of the time-average of Node 1 and Node 2 of the 50-node simulation. The number of nodes to be included in the calculation is multiplied by the grid refinement factor.

3. To report the results of this study, the Grid Convergence Index (GCI) is computed:

$$
G C I=\frac{F_{s}}{r^{p}-1}\left|\frac{f_{2}-f_{1}}{f_{1}}\right|
$$

Where $F_{s}$ is the factor of safety, $r$ is the grid refinement factor, $p$ is the order of accuracy of the algorithm used to compute the solution, and $\mathrm{f}_{1}$ and $\mathrm{f}_{2}$ are the fine and coarse mesh solutions, respectively. In our case, since time-averaging is performed, a conservative value of three is used for the factor of safety, the grid refinement factor is two as mentioned before and the algorithm used to compute temperatures in the thermocline tank is of the first order of accuracy. For further detail about this method of reporting grid refinement studies, ample explanation is provided in [13].

The GCI returns a fractional estimate of the relative uncertainty in the fine grid solution. Results obtained after the calculation of the GCI for the five grids used for the thermocline cycling test are presented in Figure 19.

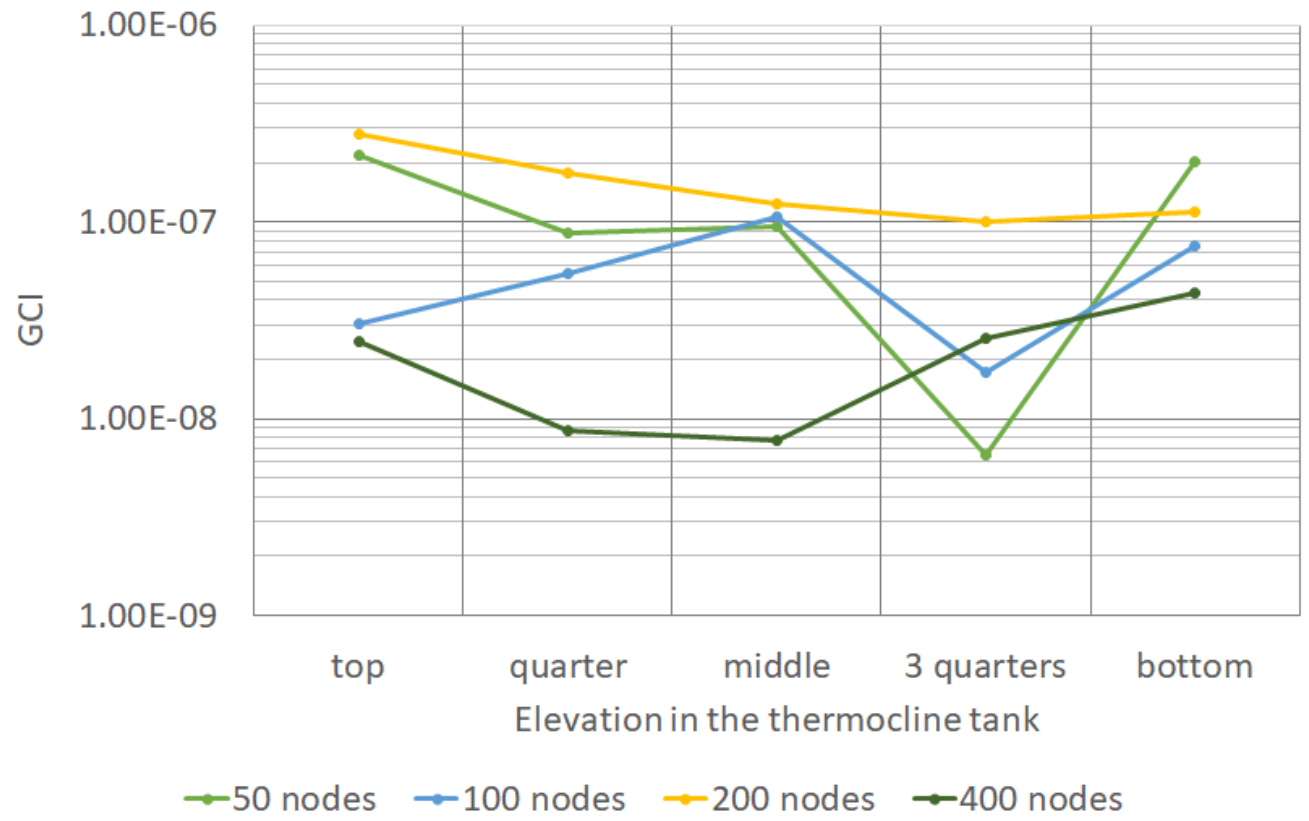

Figure 19. GCI function of mesh refinement and elevation in the thermocline tank.

The interpretation of the GCI is straightforward: for instance, at the top of the tank, the GCI value for the 50 -node mesh is about $2 \mathrm{E}-07$, which indicates an uncertainty due to the discretization process of $2 \mathrm{E}-05 \%$ in the 50-node mesh solution. We can notice that the uncertainty does not automatically decrease with an increasingly finer mesh. However, one must keep in mind that the GCI was computed from time-averaged temperatures. Furthermore, for all meshes, the uncertainty at any elevation in the tank stays below 2E-05\%, which indicates the success of this spatial convergence test. 


\section{VALIDATION}

Validation is the process of testing a computer program and evaluating the results to ensure compliance with specific requirements. It involves the execution of the code and checks whether the software meets the requirements and expectations of the customer. It can find bugs the verification process cannot and usually involves the computation of various metrics to evaluate the discrepancy between the code accuracy and the required accuracy within a specified domain. The validation process can be iterative: if the model performance is judged to low, model calibration can be performed to align model behavior more closely with reality. The updated model is then validated again. Validation metrics used for TEDS to measure the closeness of the model to reality are the Euclidean and dynamic time warping (DTW) distances, both of which can be computed via algorithms within the Risk Analysis Virtual ENvironment (RAVEN). A more in-depth discussion of each and its completion is shown in subsequent sections.

This section describes the validation methodology and analysis that was conducted. Subsections describe the various metrics used in more details, followed by a description of the workflow utilized in the calibration and validation of the models. Finally, results of the iterative validation and tuning process are presented.

\subsection{Validation Metrics Selection}

Choosing validation metrics for time series comparison is not a straightforward process and is of most relevance since divergent conclusions on the validity of the model may be obtained using different criteria [14]. Most of the usual validation metrics are only suitable to compare deterministic quantities such as a mean value or probability distributions. For strongly time-dependent system responses or response including a large spectrum of frequencies, these previous metrics are irrelevant. Metrics combining amplitude and phase errors have been developed to deal with time-dependent data, several have been reviewed in [17]. However, these metrics focus on comparing a deterministic value from the model quantities of interest (QoIs) with the estimated statistical mean of the experimental data [16]. In our case, this approach does not seem to be the most appropriate since it is more appropriate for the analysis of a waveform series. In our case, the phase component is likely to be meaningless. TEDS is not yet calibrated, and ideally, the same criteria should be used for both the calibration and validation processes. During the calibration, the goal is to reproduce the behavior of the physical system and its components. Several of TEDS components present thermal inertia (e.g., the thermocline tank) or safety lags are introduced in their control command (e.g., a delay of 10 seconds is respected before opening or closing valves when TEDS mode changes).

A more recent review presents additional metrics and criteria not as easy to interpret, but more adapted to our purpose [15]. Criteria and metrics are separated into groups:

- $\quad$ error-based measures

- information theory measures and criteria

- $\quad$ parametric and non-parametric tests

- distance-based measures and combined measures.

Advantages, drawbacks, and applicability of each one of them are discussed, thus providing pertinent information to decide on the most relevant criteria for our model validation workflows. Variability and shape are the two most important features in our case. Bias assessment could also be useful to compare a final value of a steady-state experiment and its corresponding modeling; however, the focus is on transient operations for now. Assessing the correlation or the mutual information of the experimental and model signals seem less informative in the case of transient modeling. Finally, lag assessment is not relevant since it is mainly destined to be used to compare a series with sinusoidal or waveform behavior among the measures and criteria identified for variability and shape assessment. 


\subsection{Euclidean Distance Metrics}

The Euclidean distance metric is the standard metric typically used to gain a first order approximation of the fit between two sets of data whether that be a code-to-code or code-to-experiment comparison. The Euclidean distance metric compares two time series $\mathrm{S}=\left\{\mathrm{s}_{0}, \mathrm{~s}_{1}, \ldots, \mathrm{s}_{\mathrm{T}}\right\}$ and $\mathrm{Q}=\left\{\mathrm{q}_{0}, \mathrm{q}_{1}, \ldots, \mathrm{q}_{\mathrm{T}}\right\}$ according to:

$$
d^{E u c l}(S, Q)=\sqrt{\sum_{i=0}^{T}\left(s_{i}-q_{i}\right)^{2}}
$$

Each point in $\mathrm{S}$ is directly compared with the opposing point in $\mathrm{Q}$, as shown in Figure 20 . This performance metric is computationally cheap and very fast to run, but sensitive to offset translation (i.e., time delays) and requires time series of identical length. Thus, an additional preprocessing layer is required for systems where different data lengths are provided, such as between two sets of experimental data, or outputs from various codes. However, despite these limitations, the Euclidean distance metric remains a highly effective and competitive metric for $V \& V$ purposes.

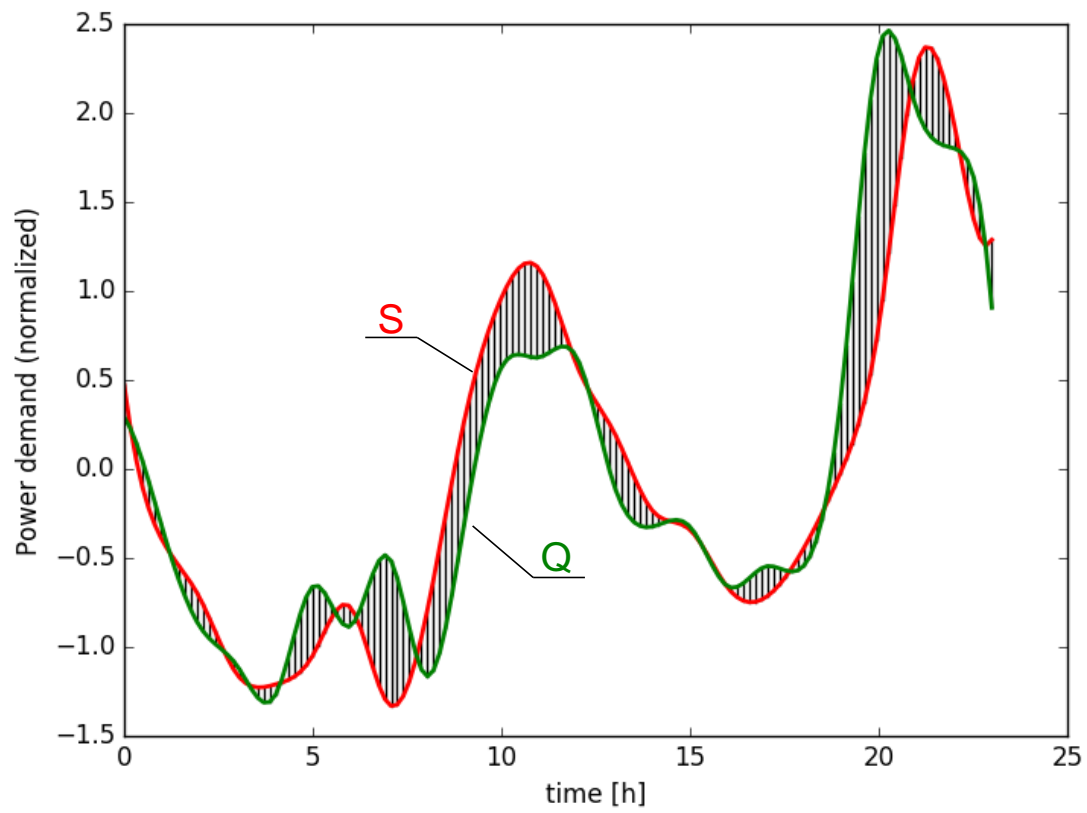

Figure 20. Euclidean distance metrics.

\subsection{Dynamic Time Warping}

DTW is a distance metric that is used to measure the similarity between two temporal sequences. DTW presents an improvement over the Euclidean distance metric in that it does not require a time series of the same length, is able to handle the offset of a time series caused by system delay or measurement shifts, and it can handle outliers/noise that is not well handled by the standard Euclidean distance metric.

DTW presents a global minimization problem between the two time series where each element of the first time series is linked to the closest matching element of the subsequent time series in a contiguous fashion. Given two time series: $X=\left\{x_{1}, x_{2}, \ldots, x_{n}\right\}$ and $Y=\left\{y_{1}, y_{2}, \ldots, y_{m}\right\}$ of length $n$ and $m$, the first step of the DTW algorithm is to compute an $\mathrm{n} \times \mathrm{m}$ distance matrix. 


$$
\text { distMatrix }=\left(\begin{array}{cccc}
d\left(X_{1}, Y_{1}\right) & d\left(X_{1}, Y_{2}\right) & \cdots & d\left(X_{1}, Y_{m}\right) \\
d\left(X_{2}, Y_{1}\right) & d\left(X_{2}, Y_{2}\right) & & \\
\vdots & & \ddots & \\
d\left(X_{n}, Y_{1}\right) & & & d\left(X_{n}, Y_{m}\right)
\end{array}\right)
$$

The objective of DTW is to find the warping path $\mathrm{W}=\left\{\mathrm{w}_{1}, \mathrm{w}_{2}, \ldots, \mathrm{w}_{\mathrm{k}, \ldots}, \mathrm{w}_{\mathrm{K}}\right\}$ of contiguous elements on the distMatrix (with $\max (\mathrm{n}, \mathrm{m})<\mathrm{K}<\mathrm{m}+\mathrm{n}-1$, and $w_{k}=\operatorname{distMatrix}(i, j)$ ), such that it minimizes the following function:

$$
\operatorname{DTW}(T, S)=\min \left(\sqrt{\sum_{k=1}^{K} w_{k}}\right)
$$

Through this optimization process, a minimized path can be found between the two time series ( $\mathrm{S}$ and Q), as shown in Figure 21 and Figure 22. The mapping of the curves is not a direct vertical mapping as was shown in the Euclidean distance measure. Thus, presenting the benefits that DTW can work with small time delays and time series of varying lengths. However, a downside of DTW is the additional computation time required to make the comparisons, particularly when the datasets become quite large.

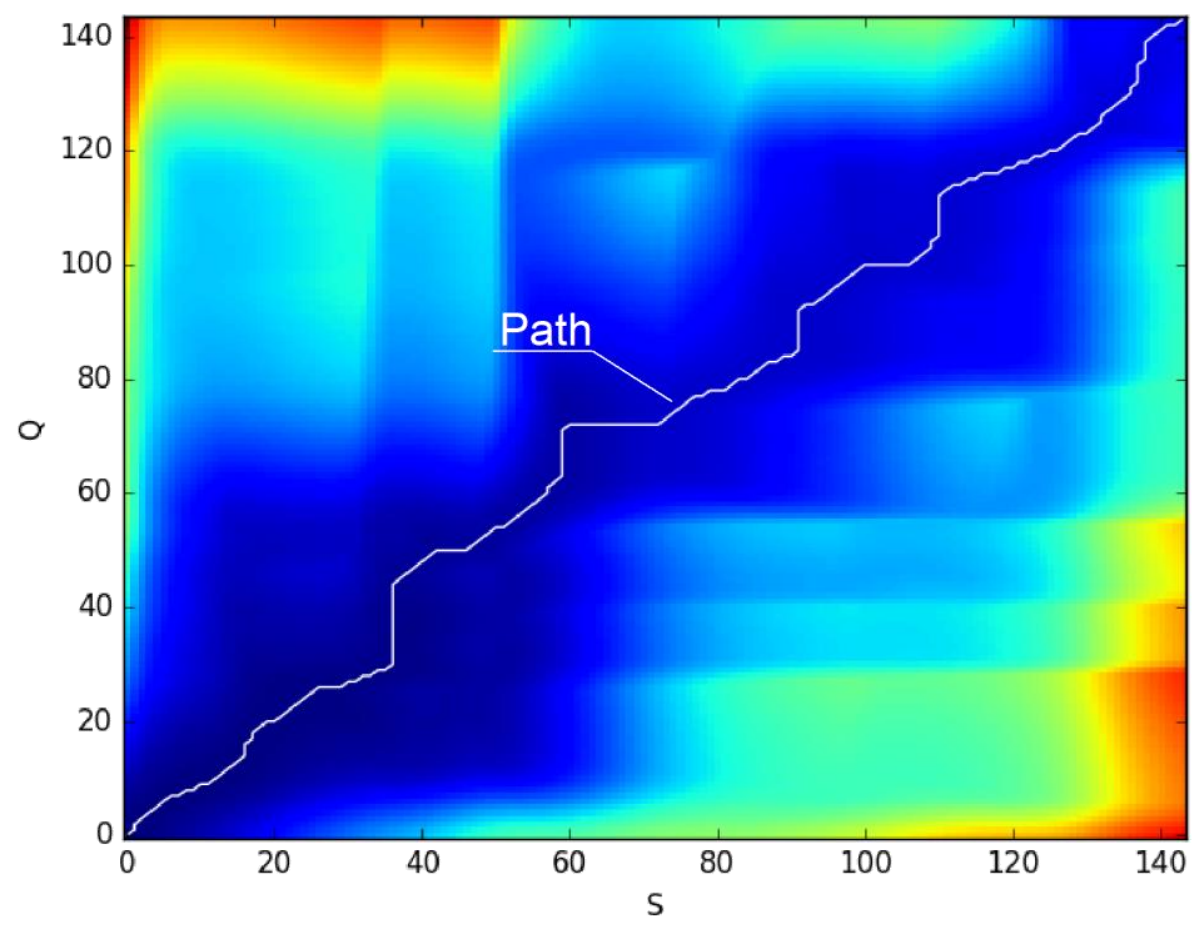

Figure 21. Minimized path between curves S and Q [18]. 


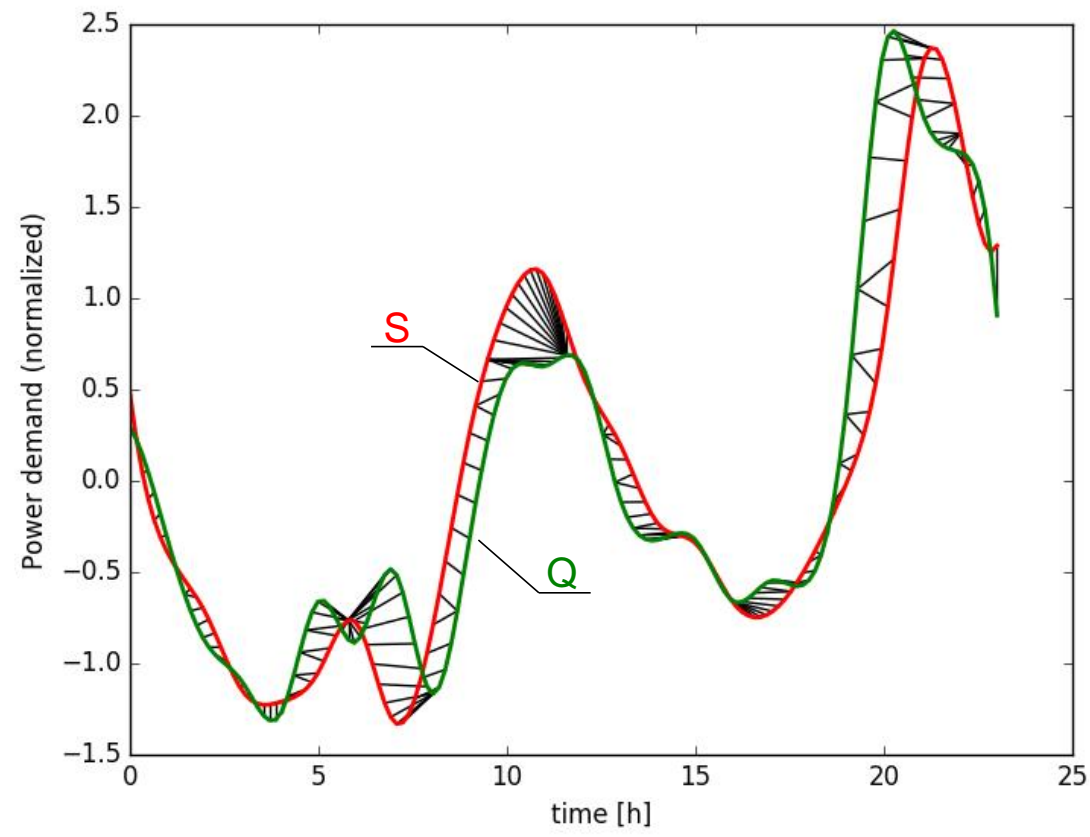

Figure 22. DTW mapping of S and Q for normalized power demand.

\subsection{Workflow}

A validation workflow template has been created in RAVEN to both validate and tune the Modelica models of TEDS. The workflows, depicted in Figure 23 and Figure 24, have a series of steps that are defined below:

- PreProcess Create HistorySet: This step serves to take experimental data from the TEDS facility and process it into a HistorySet readable and usable by RAVEN. This step instantiates an external python model for the preprocessing.

- Optimizer: In this step of the RAVEN workflow, any number of the previously created RAVEN optimization routines can be called (e.g., finite difference, central difference, gradient descent, SPSA). The goal of the step is to calculate the target evaluation of the problem; in this case, a metric value, and compare it to a previous run solution and then pick either state the solution is converged in or modify an input parameter in the parameter space to move closer to the target evaluation.

- Run Dymola Executable: This step executes the Dymola model using an external model code interface that was developed for interacting with the Dymola initialization file $d s i n . t x t$ and then executing via a command line the updated Modelica model.

- Metrics: The metrics are calculated via post-processors within RAVEN. Classical metrics, such as Euclidean distance, require the compared HistorySets to have an equal size, whereas metrics such as DTW do not. Therefore, in the case of classical metrics, a time series syncing step is required where the history sets of both the model and the experiment are mapped to having an equal length.

- PlotOptimized Walk/Solution Path: The final solution path that shows how the optimization of the system progresses as the optimizer solves the system.

An example RAVEN workflow in extensible markup language (XML) is provided in Figure 25 where the initial TEDS startup data is being compared with a particular run of a Modelica model. This process will provide users with an automated way to validate and tune their models in accordance with the metrics selected over a particular operating regime of the code. 
Experimental Data: Time Series of Temperatures, Pressures, Flows

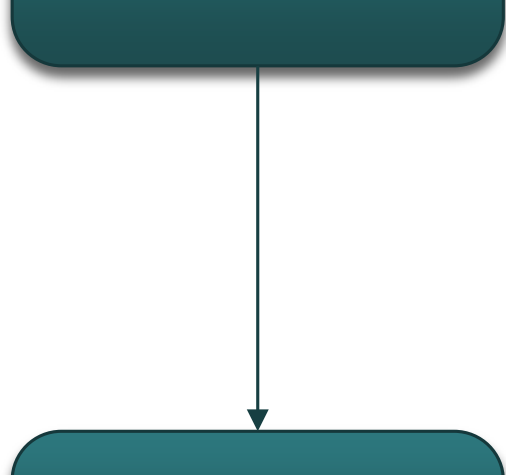

Model Parameters to tune Identification

Pre-process: Load into HistorySet

Sample Initial parameters according to initial conditions

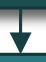

Modify Dymola Initial Conditions

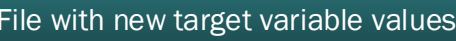

4

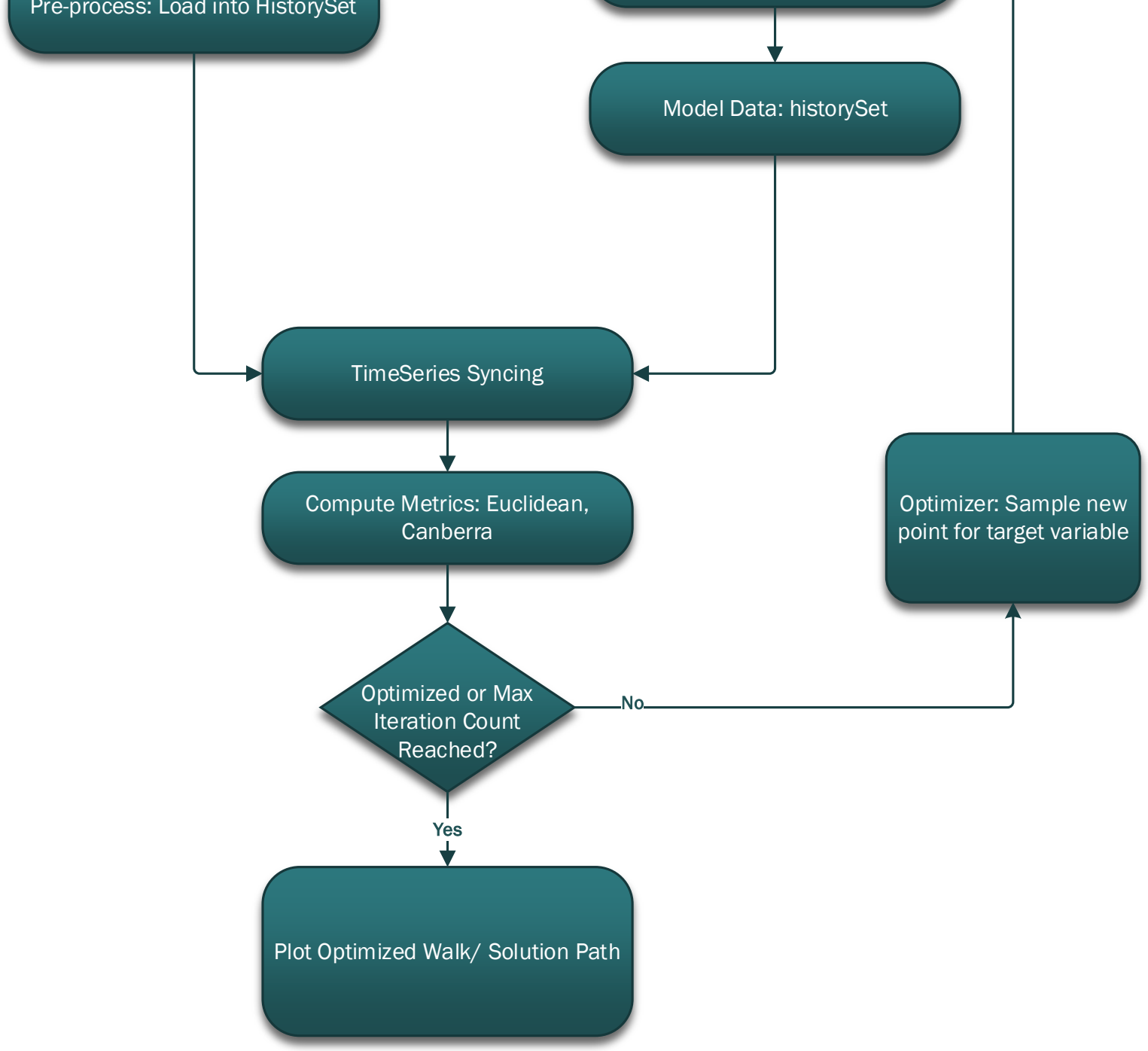

Figure 23. RAVEN V\&V workflow for comparing classical metrics. 


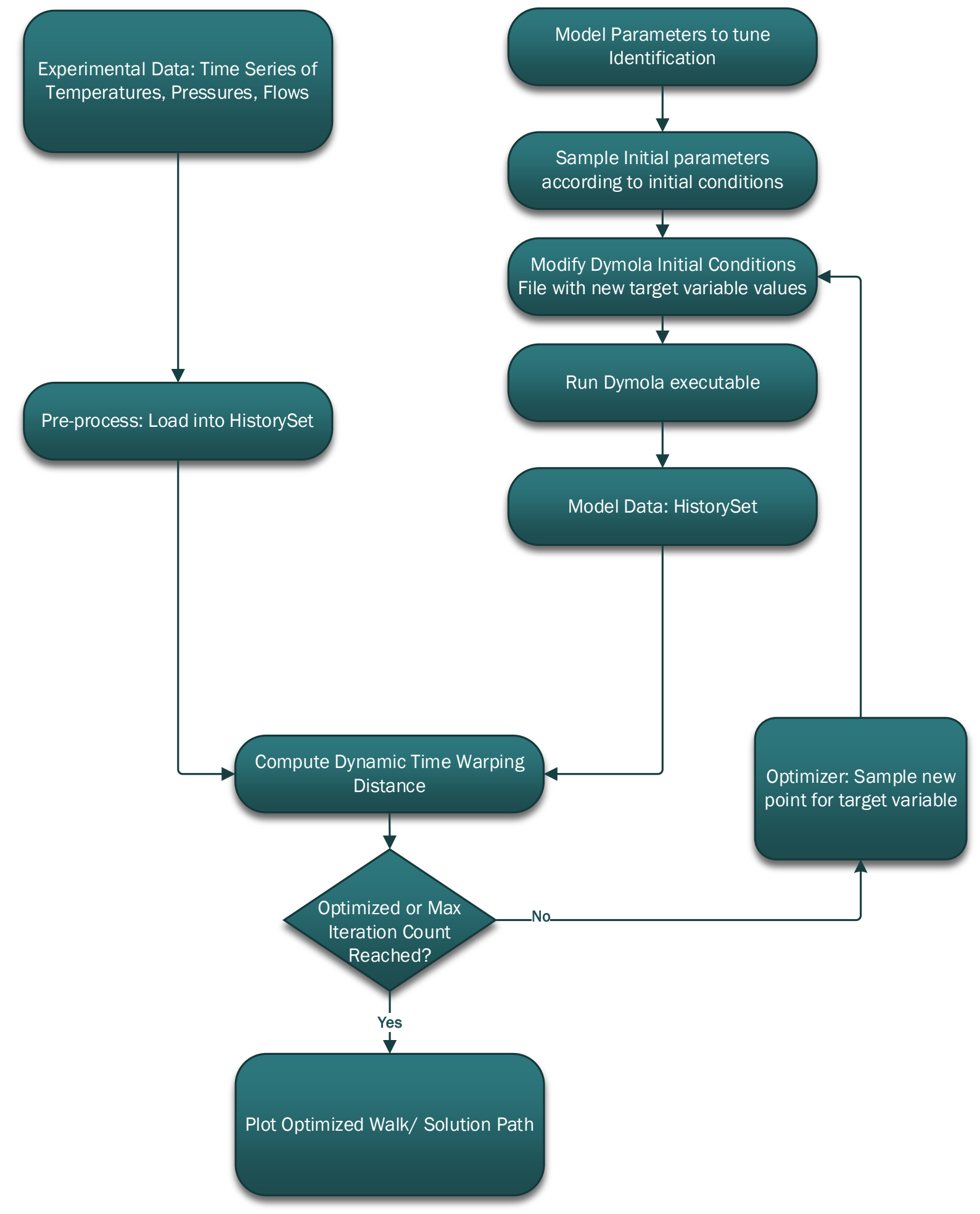

Figure 24. RAVEN V\&V workflow using DTW as the comparison metric. 


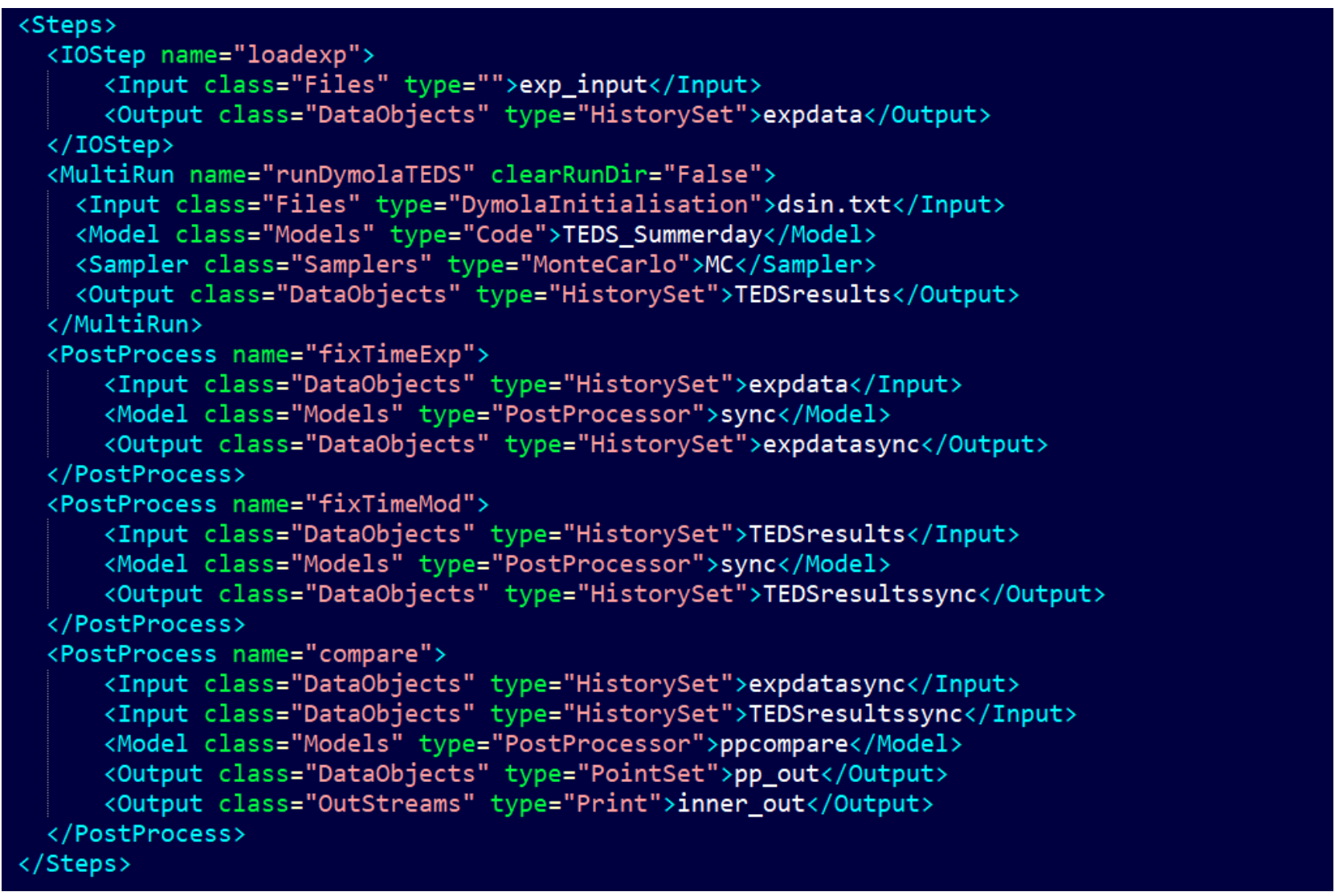

Figure 25. Example RAVEN XML workflow for the validation of classical metrics.

\subsection{Code-to-Code Comparison}

To ensure the RAVEN workflow works as intended, a code-to-code comparison was performed. The experimental data was replaced by data from a transient of the TEDS Dymola model — charging the thermocline tank until all temperature points are at $200^{\circ} \mathrm{F}$, with an ambient temperature of $20^{\circ} \mathrm{C}$, and the thermocline's temperatures are initialized at $70^{\circ} \mathrm{C}$. The thermocline tank porosity was set to 0.9 and the shape factor to 3.5. The aim of this study was to see if the RAVEN optimization would indicate that these values for the porosity and the shape factor led to the minimal distance between the model and the "experiment."

To test the code-to-code optimization workflow, three optimization studies were conducted: (1) the system could vary the tank porosity to match the thermocline temperature at the top of the tank; (2) the porosity was varied to match the bottom of the tank temperature; and (3) the shape factor could be varied to match the temperature at the bottom of the tank.

Figure 26 and Figure 27 show the results of this code-to-code comparison, respectively examining the ability of the RAVEN workflow to optimize the model using the thermocline porosity and shape factor. On both figures, we see that the distance is minimum for the value of the parameter corresponding to the reference model data. The RAVEN workflow is thus optimizing the model's parameter. 


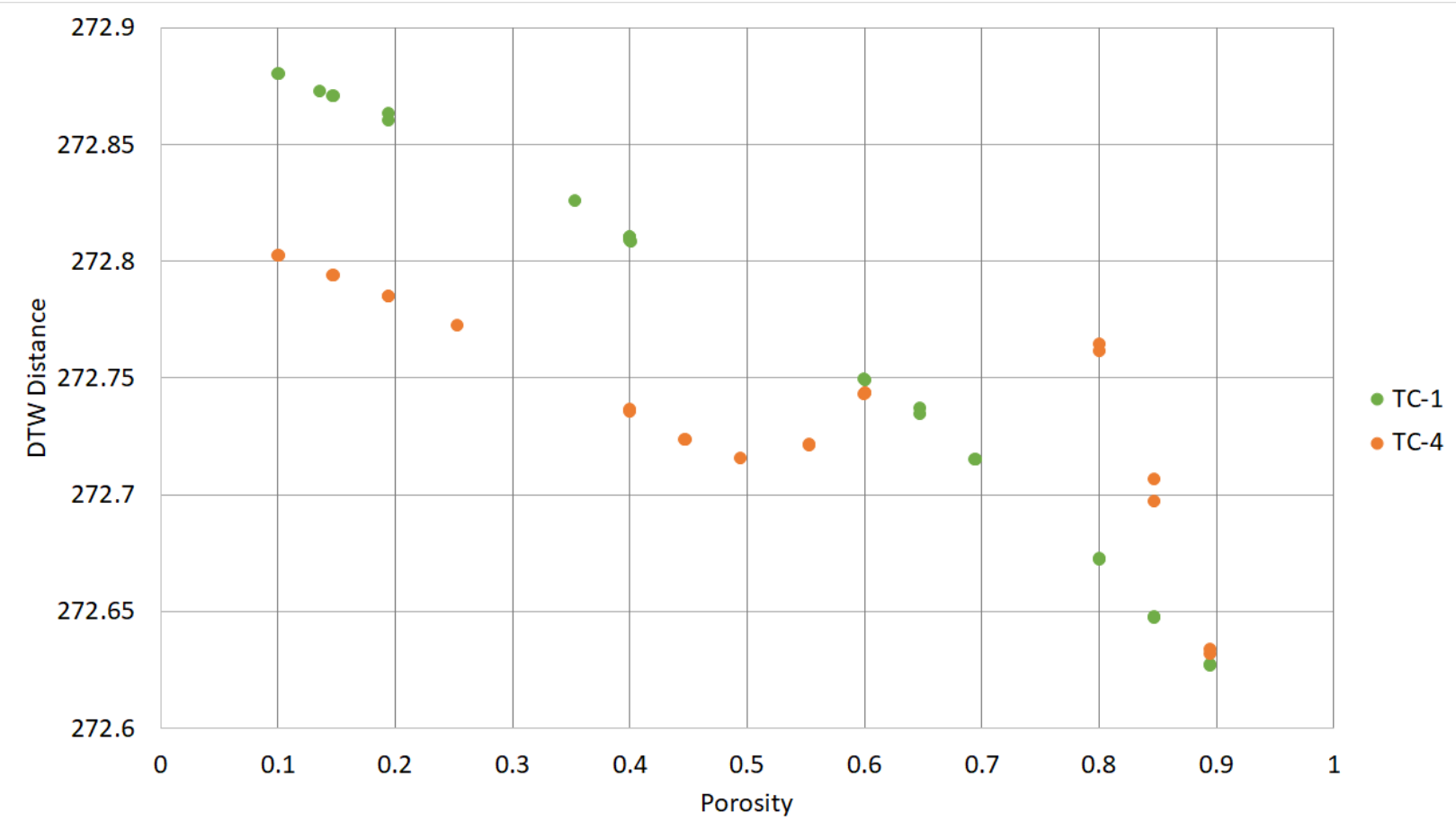

Figure 26. TEDS code-to-code comparison. DTW distance between the reference data (porosity $=0.9$ ) and the model data (TC-1, thermocline top temperature; and TC-4, thermocline bottom temperature) function of the thermocline porosity.

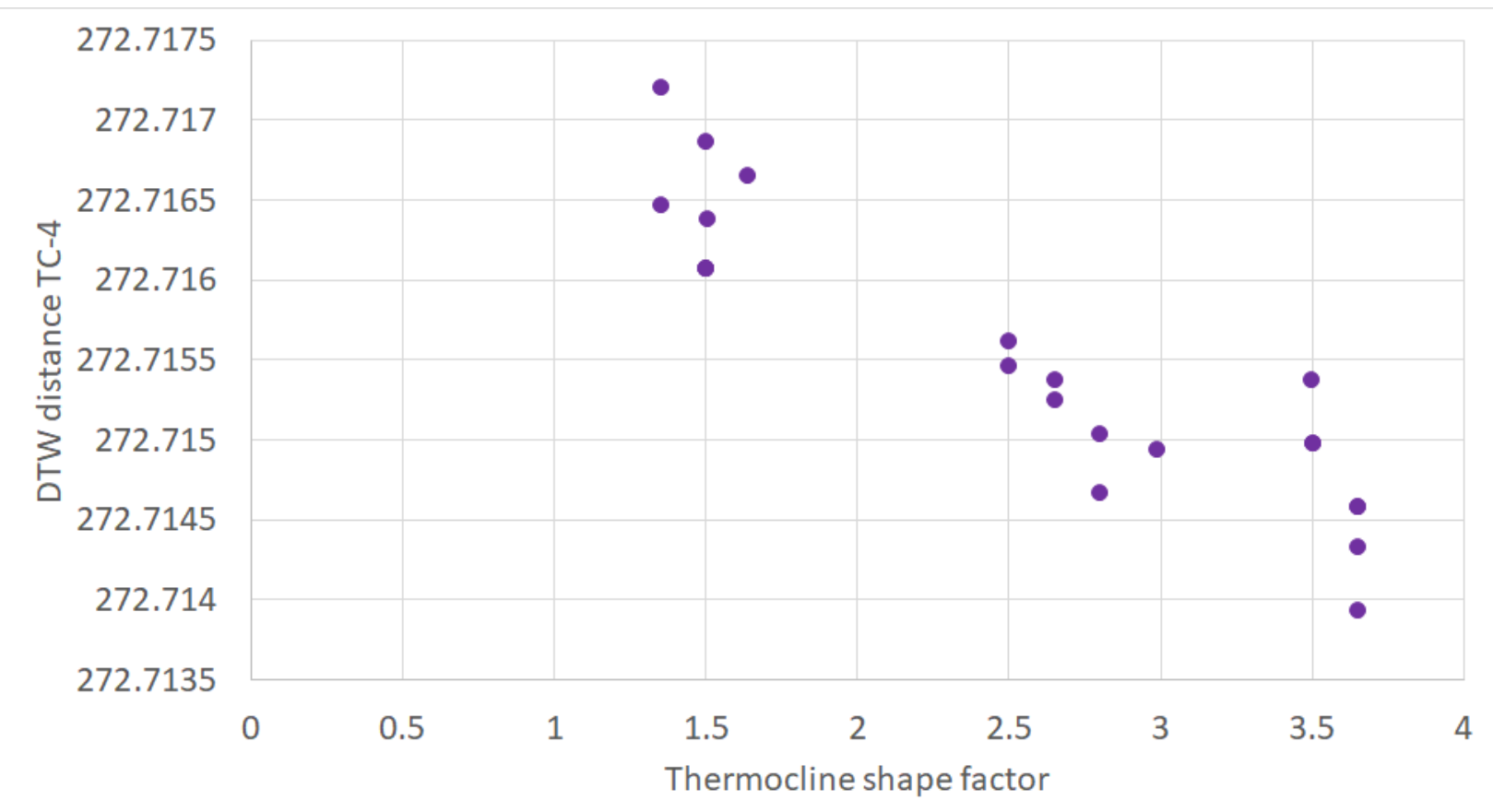

Figure 27. TEDS code-to-code comparison. DTW distance between the reference data (shape factor $=3.5$ ) and the model data (TC-4, thermocline bottom temperature) function of the thermocline shape factor. 


\subsection{Initial Conditions for the Modelica Models}

Upon the initial startup of TEDS, a series of tests were conducted to ensure the system is operating according to lab procedures. The tests are meant to act as a shakedown of the facility, making sure all the operating modes are possible and the wide range of operating pressures and temperatures can be met with the experimental facility. Such operations and data streams are invaluable to the validation procedure, and ultimately, the tuning of the dynamic component models.

Well-defined boundary and initial conditions are essential to properly compare data from the experimental facilities with the Dymola models. This is of particular importance given the nonlinear nature of many of the system components, such as pipes, heat exchangers, and PID controller units. Therefore, for each mode in the test matrix that will be used for validation, a specific initialization of the model is required.

The initialization for a particular run is defined as the initial conditions for that run or, in chronological order, the endpoint of the previous run. As an example, in the startup sequence it is envisioned that the test matrix will begin to operate in charging mode (Mode 2) until TC-201 (temperature of the tank charging line) and all thermocline temperatures read $100^{\circ} \mathrm{F}$. Then the system will begin to discharge until all systems $\operatorname{read} 70^{\circ} \mathrm{F}$.

The process of designing the initial conditions for discharge is by simulating the end point of the charging mode and is detailed below; the process is similar for other initial conditions requirements.

The test prior to discharge in the test matrix consists of running TEDS in charging mode (Mode 2) until TC-201 (temperature of the tank charging line) and all thermocline temperatures read $100^{\circ} \mathrm{F}$. To accomplish this the steps below were followed to define a relevant control scheme for this startup condition. Note: Controllers detailed in Sections 4.2 and 4.3 are relevant to nominal control; startup control is not included in these.

1. To charge the thermocline tank, valve 2 must be open, so the overall demand and the thermal generator demand must be defined to induce a negative thermal storage demand. Therefore, we defined a null total demand and a $100 \%$ heater demand.

2. The thermocline should be brought to $100^{\circ} \mathrm{F}$, so $\mathrm{T}_{-}$hot_design is set to $100^{\circ} \mathrm{F}$ and $\mathrm{T}_{\text {_cold_design }}$ to $50^{\circ} \mathrm{F}$.

3. To speed up the simulation an artificial temperature difference of $100^{\circ} \mathrm{F}$ replaces the $\mathrm{T}_{-}$hot_design $\mathrm{T}_{\text {_cold_design in }}$ the computation of the charging mass flow (see Equation 2) and for each node in the thermocline tank the filler and the fluid temperatures are initialized at $30^{\circ} \mathrm{C}$ (instead of $325^{\circ} \mathrm{C}$ ).

4. During the test, the volume flow rate is maintained constant at 14 gallons/min, to respect this constraint the control of valve 1 is modified. A volume flow rate sensor is added on the charging Fahrenheit degree line to the thermocline tank and the error used to control the opening of valve 1 (GBV-201) is re-defined as follows:

$$
\text { Error }_{1}=\left|\frac{v_{T E S \text { Demand }}-v_{\text {TES charging }}}{v_{\text {TES Demand }}}\right|
$$

where $v_{T E S}$ Demand is the nominal volume flow rate expressed in the relevant units and $v_{T E S}$ charging is the volume flow rate measured by the sensor on the thermocline tank charging line.

5. Finally, the simulation is run for $14400 \mathrm{~s}(5 \mathrm{~h})$. Results are shown in Figure 28 and Figure 29, respectively representing the opening signals sent to valve 1 and valve 2 , the volume flow rate through valve 1 and the temperatures at the top, middle-point, bottom of the thermocline tank and on the charging line. In Figure 28, we can observe that the valve 1 is opening and letting in the thermocline tank a constant mass flow rate of hot fluid as expected. For clarity, opening signals for valves 3, 4 and 5 have not been represented but the signals were consistent with TEDS operating in Mode 2. Depicted in Figure 29, the thermocline and charging line temperatures all reach a constant 
value of $37.78^{\circ} \mathrm{C}\left(=100^{\circ} \mathrm{F}\right)$ at the end of the simulation. Initial temperature overshoot in the thermocline is due to initially stagnant flow in the Chromalox heater that is heated above the setpoint temperature and then must make its way through the thermocline in charging mode.

At this point the system is initialized at $100^{\circ} \mathrm{F}$ in all sections of the thermocline and the valving system is set for charging. Saving this initialization state of the model allows users to utilize this as a potential starting point from which to begin system operation.

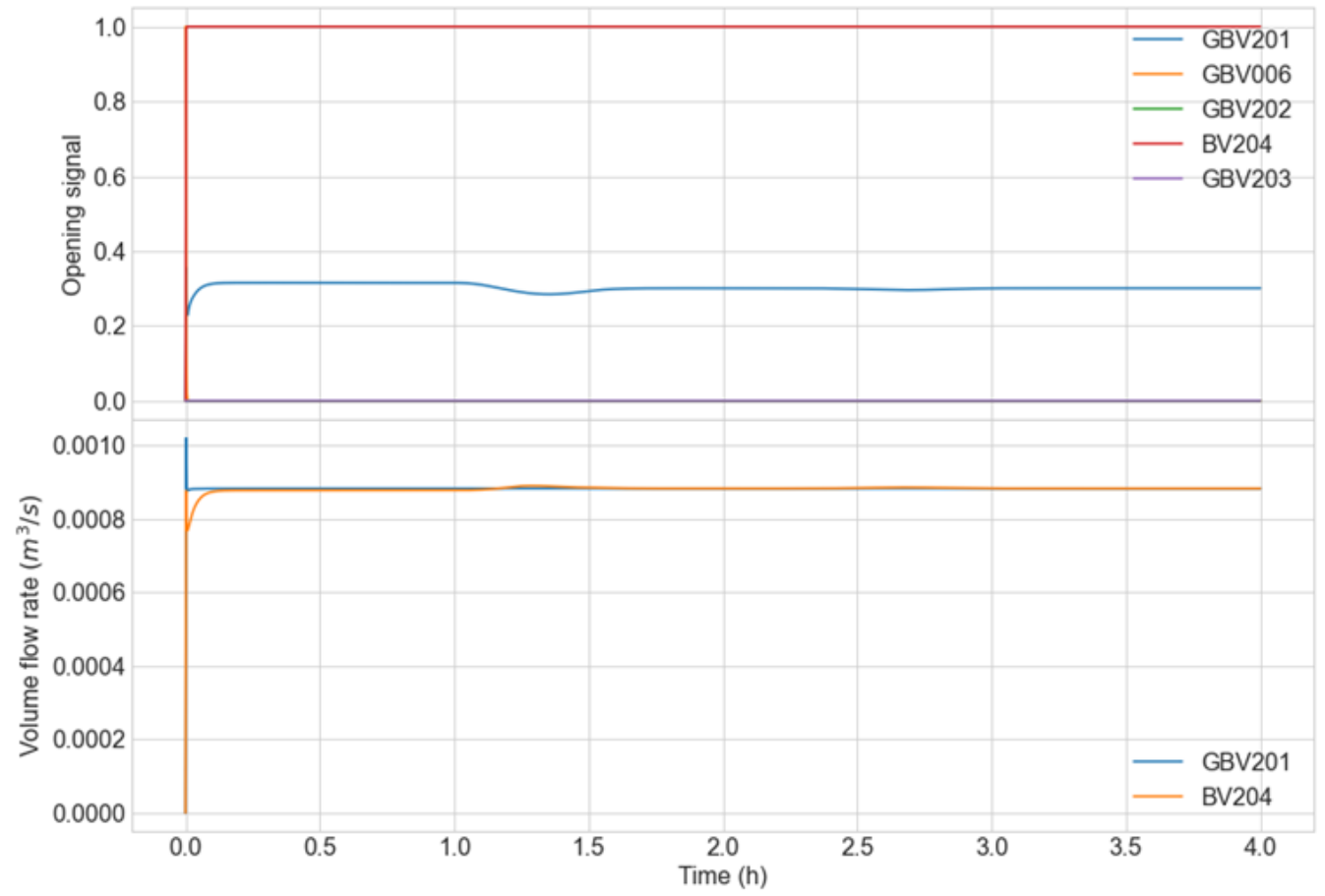

Figure 28. Valve opening signals and volume flow rate through valve 1 and 4 during charging run to $100^{\circ} \mathrm{F}$. 


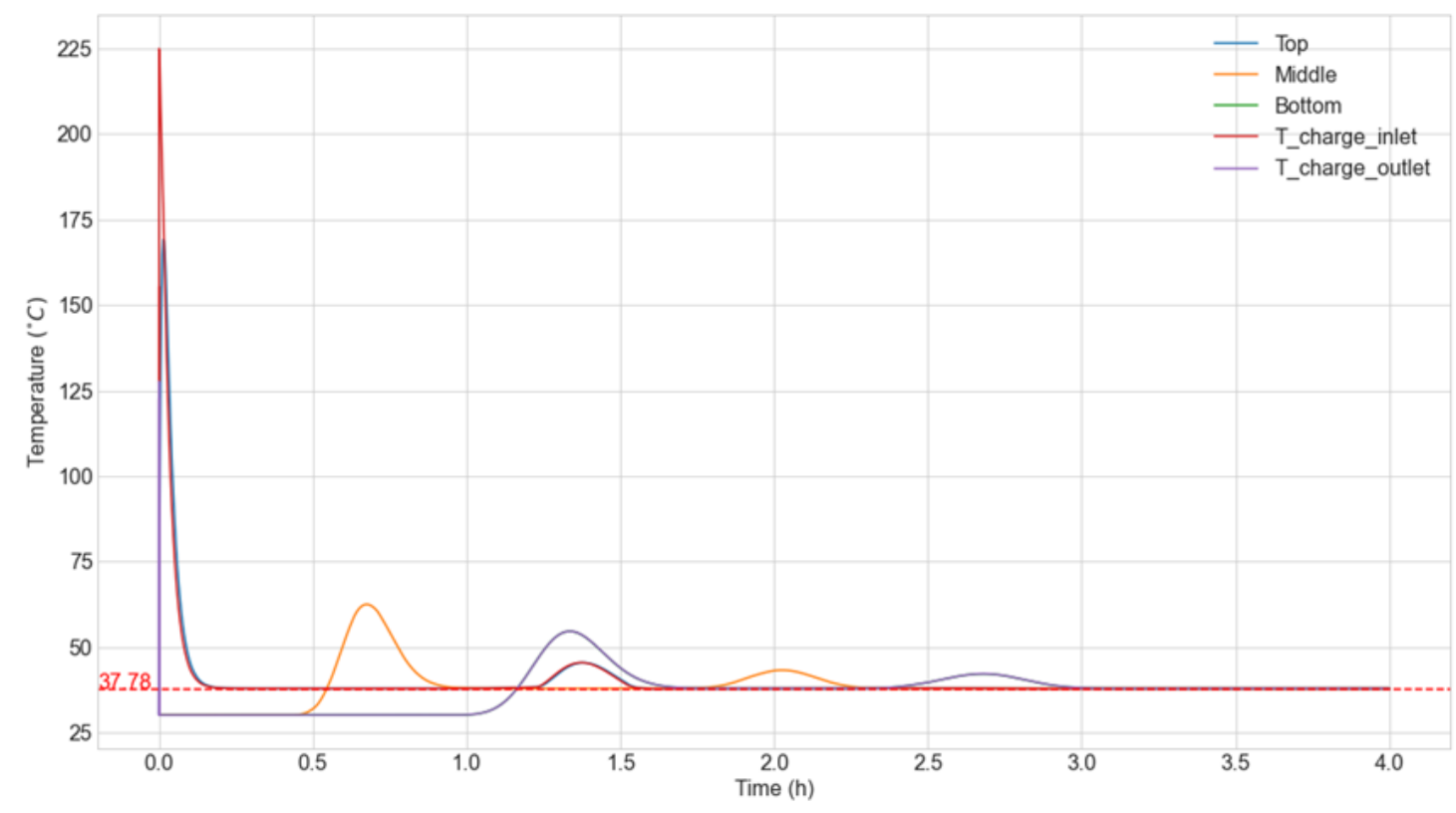

Figure 29. Temperatures in the thermocline and on the charging line during charging.

Following charging, TEDS runs in discharge mode (Mode 3) until all thermocline temperatures read $70^{\circ} \mathrm{F}\left(=21.11^{\circ} \mathrm{C}\right)$. As illustrated in Figure 30, valve 1 (GBV-201) and valve 4 (BV-204) will stay closed while the valve 3 (GBV-202) and valve 5 (GBV-203) will open to allow hot fluid to leave the thermocline tank and cold fluid to replace it from the bottom up. The following operating parameters were chosen to simulate this test step:

1. The $\mathrm{T}_{-}$hot_design was set to $100^{\circ} \mathrm{F}$, and $\mathrm{T}_{\text {_cold_design }}$ to $70^{\circ} \mathrm{F}$, the temperature to reach.

2. To discharge the thermocline tank, the overall demand and the thermal generator demand must be defined to induce a positive thermal storage demand. The total demand was set to $110 \%$ while the heater demand was set to 0 .

3. Finally, the simulation is run for about $4 \mathrm{~h}$, the time needed for the thermocline temperatures to reach the target of $70^{\circ} \mathrm{F}\left(=21.11^{\circ} \mathrm{C}\right)$. Results are shown in Figure 31. We observe that the target temperature is indeed reached in the thermocline tank and the opening signals sent to the valves during the simulation are consistent with TEDS running in Mode 3.

Once completed the final solution can be saved in state as a potential starting point from which system operation can begin in the future. The creation and utilization of these states is vital for validation studies to be valuable. 


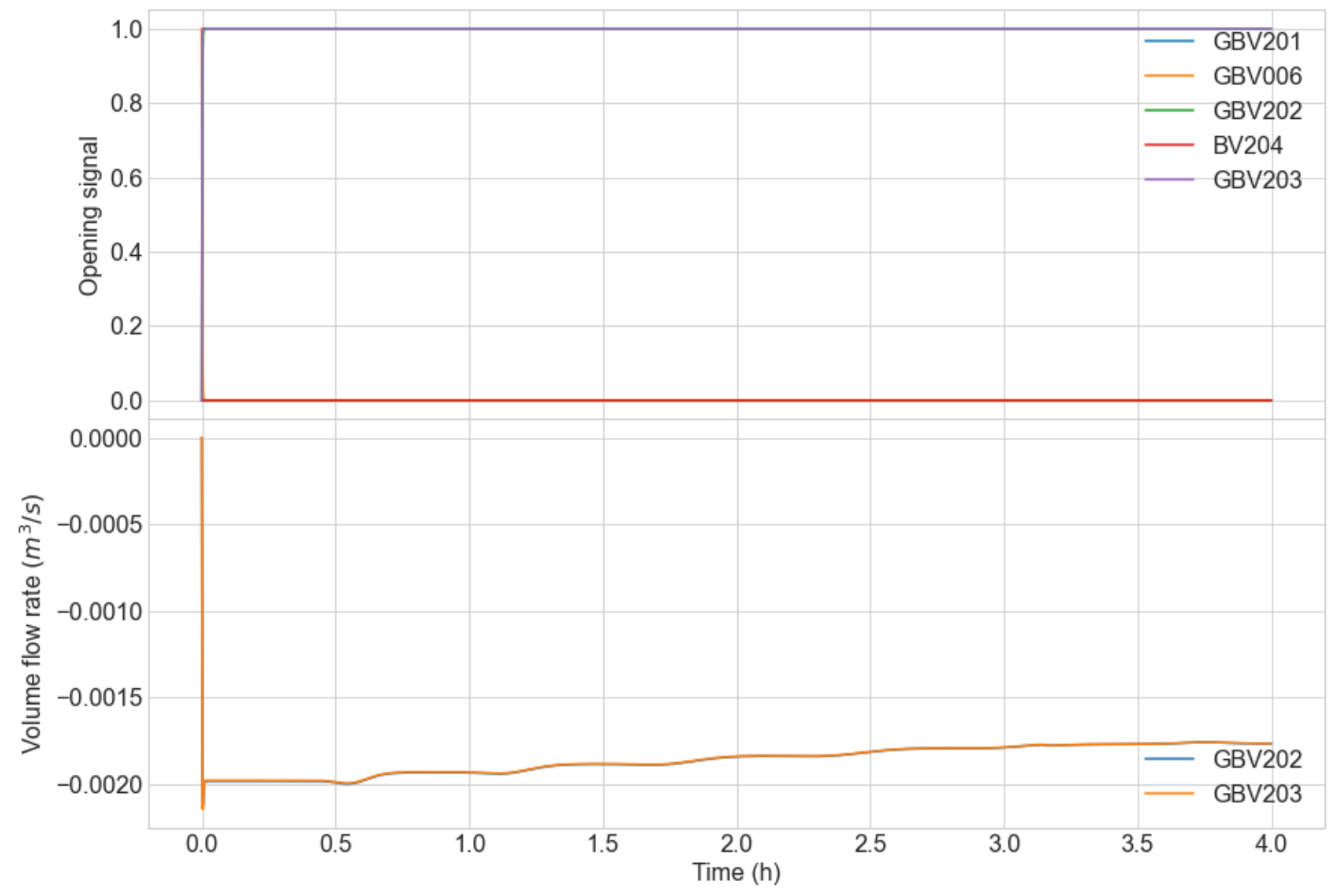

Figure 30. Valve opening signals and volume flow rate through valves 3 and 5 during step 8 of the test matrix.

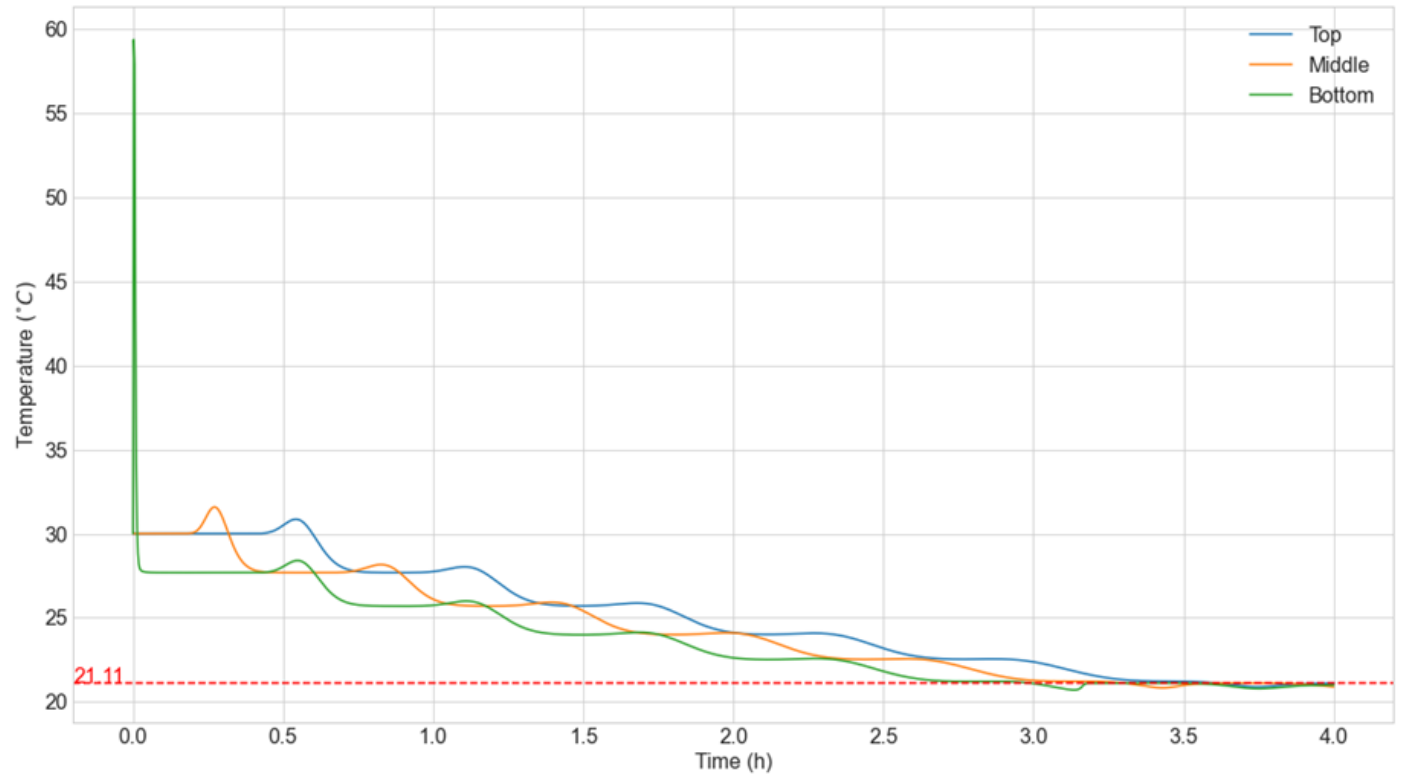

Figure 31 . Temperatures in the thermocline during step 8 of the test matrix. 


\subsection{Initial Results}

This section serves to provide initial results of the validation and tuning methodology outlined in the previous section. Parameters of interest and optimization were selected based on expert knowledge of system. Simulations selected were based upon available data from the experimental facility that fall within a solution space of nominal operating modes. Due to unforeseen issues with the experimental system, TEDS is offline for maintenance and initial startup data is sparse. Therefore, initial results will be used to demonstrate the methodology for code-to-experiment simulation with full validation and mapping taking place as a future task when the experiment is back in operational order.

Initial experimental results used for comparison are available from a four-hour charging loop heat up to $300^{\circ} \mathrm{C}$ with initial thermocline tank temperatures of $120^{\circ} \mathrm{C}$ and pipe temperatures of $50^{\circ} \mathrm{C}$. The optimization workflow will use DTW as the metric of interest. The simulation input parameter to be varied is the tank porosity with the target output being the average temperature at the bottom of the thermocline tank (TC-4). Simulation setup included:

1. Setting loop flow to a constant value of 12 gallons/min.

2. Placing the heater setpoint temperature to $300^{\circ} \mathrm{C}$ with a maximum input of $200-\mathrm{kW}$.

3. Directing all flow to the thermocline tank (e.g., Mode 2 Operation).

4. The input parameter porosity was constrained to be between 0.2 and 0.8 with an initial starting value of 0.5 .

Results, shown in Figure 32, illustrate the convergence of the porosity from the initial starting point of 0.5 to 0.2 over seven accepted steps in the RAVEN optimizer routine. The difference between the initial porosity value of 0.5 to the endpoint value of 0.2 compared with the experimental data is portrayed in Figure 33. These results demonstrate that initial porosity values used in the simulation led to tank heat up rate that far exceeded the experimental results.

As the porosity in the tank decreased to the endpoint value of 0.2 , the mismatch between the simulation and experiment is lessened. This demonstrates the ability of the methodology to automatically tune the model. It is noted that the experiment does not exactly overlap with the model. This mismatch during startup is because the experiment has an oscillatory mass flow rate as the fluid begins to heat up, lowering viscosity and increasing the mass flow rate since the pump operates on a constant frequency drive. Therefore, these initial test case runs are meant to show the ability of the system to modify the code to align with experimental results more closely. Once the experiment resumes operation the pump curves will be utilized to maintain a constant mass flow rate, and sensor data will be double checked to ensure heater inputs and flow rates align with the expectations of the model and experts. 


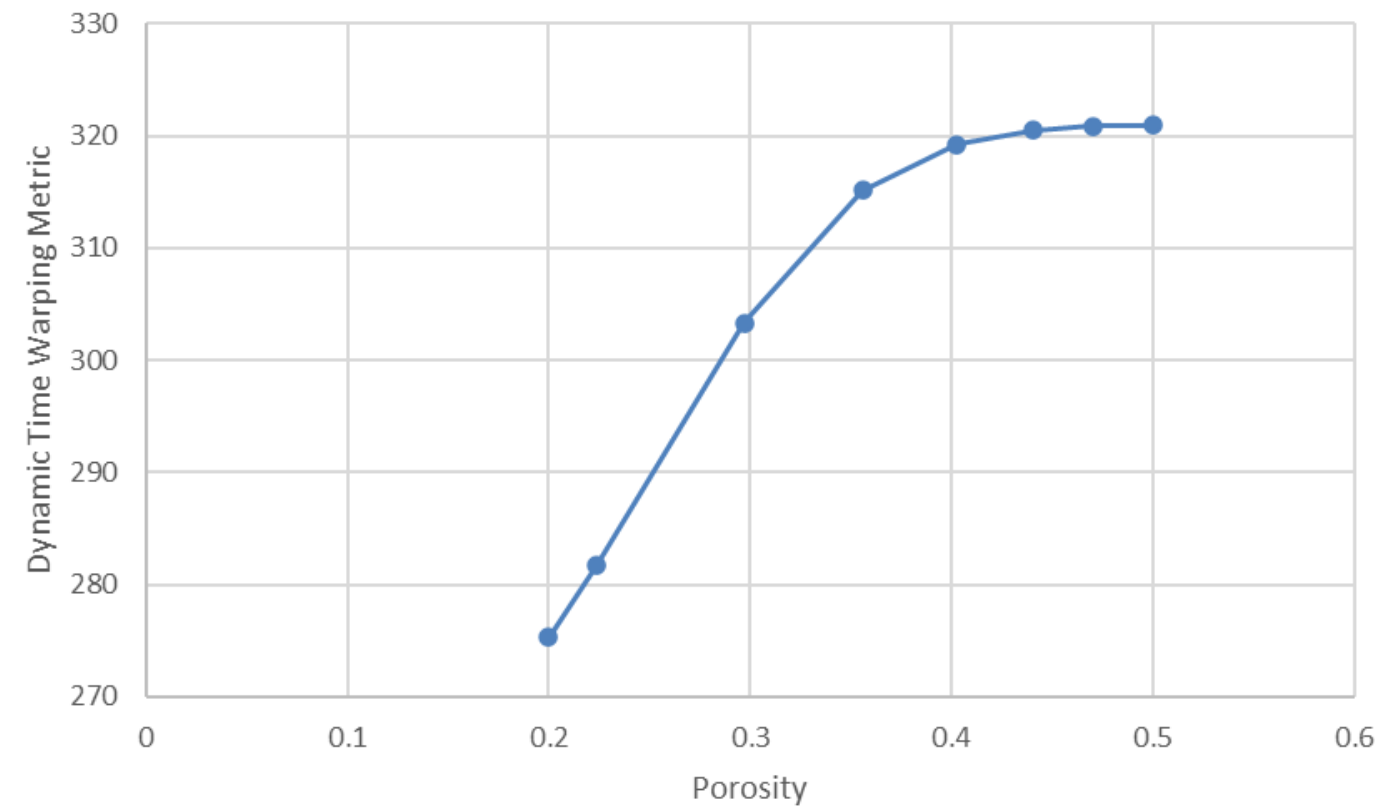

Figure 32. DTW optimization metric for thermocline porosity as a function of the thermocline exit temperature (TC-4).

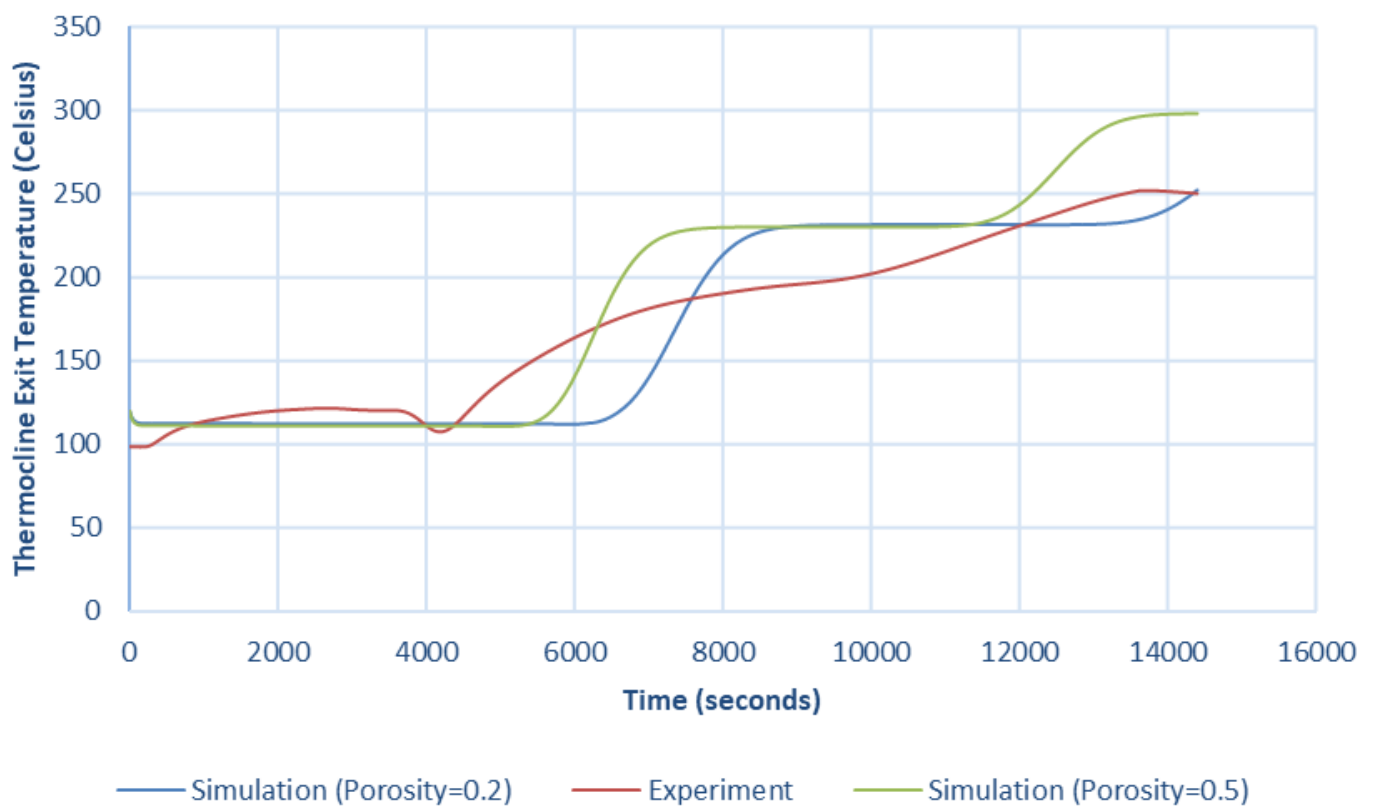

Figure 33. Thermocline exit temperature from the initial simulation point with a porosity of 0.5 to the end point of porosity 0.2 .

\section{CONCLUSIONS}

This report provides an overview on the V\&V of the TEDS model developed in the Modelica process modeling ecosystem using experimental data. 
As described in this report, model development has led to the creation of a dynamic systems-level model of the experimental TEDS facility in the Modelica language, capable of operating under all potential modes set forth by the design team. The development included the creation of property modules for Therminol-66, alumina, FOAMGLAS $®$ ONE, and ethylene glycol (DowTherm SR-1) that have been incorporated in the TRANSFORM library at ORNL. Control algorithms have been developed to be consistent with exposed variables within the experimental facility to allow for the seamless integration of control algorithms proposed in this report. The model includes the primary components of the TEDS experimental unit, including a 200-kW Chromalox heater, a single-tank packed-bed TES system filled with 0.125-in. alumina, an ethylene-glycol-to-Therminol-66 heat exchanger, system piping, five control valves, and all associated temperature, pressure, and mass flow sensors.

The model was used during the preconstruction phase of the experimental effort to inform experimental design (e.g., insulation requirements, bypass line placement, expected performance of components) and to test innovative control schemes prior to the initial operation. Through simulation, it was determined that a 6-in.-thick layer of FOAMGLAS $®$ ONE insulation was required for the thermocline tanks to help minimize heat losses while still fitting within the physical footprint of the experiment. Additionally, it was determined that a bypass line on the Therminol-66 side of the heat exchanger or a minimum ethylene glycol mass flow rate is required to ensure zero boiling of the ethylene glycol can occur in either Mode 4 or Mode 2 operation. This requirement is leading to the inclusion of a bypass line on the oil side of the oil-glycol heat exchanger that was not previously envisioned.

Using IEEE V\&V methodologies, considered the gold standard in the engineering field, the model was verified using a combination of static analysis, spatial convergence, and regression tests. Then, using a combination of classical Euclidean point-to-point comparison techniques alongside DTW, a validation workflow was constructed using RAVEN to compare the model results with the experimental results. As part of the validation workflow, an additional tuning step was added to allow for empirical values within the model to be tuned via an iterative process to align with experimental results more closely over planned operating regimes. This tuning is required to account for physical phenomena that are less understood within the empirical heat transfer correlations and geometry effects in the system. Parameters tuned include the thermocline packing factor, the thermocline shape factor for heat transfer between the solid and fluid regimes, and the heat exchanger effectiveness coefficient. A code-to-code comparison of this tuning workflow demonstrated that the methodology is capable of converging to the proper solution. Initial runs using the workflow to compare experimental results with the model and tune the model parameter space have been conducted. Initial results demonstrate positive results on the ability of the methodology to tune the model. Once the experimental facility resumes operation, additional validation and tuning of the models and in-depth analyses can be run.

Through the commencement of this work, a verified systems-level model of TEDS with associated control systems, sensors, piping diameters, and component capabilities has been created. This model was utilized in the pre-experimental phase to inform system design, insulation thicknesses, and potential control schemes to operate the system effectively and safely. Then initial experimental startup and operational data was used to begin to validate and tune components of the TEDS model to match the experiment more closely over the operating regime. Thus, demonstrating the classical two-step approach of a model informing experimental design followed by the experiment validating and tuning the model.

\section{FUTURE WORK}

Delays in the operation of TEDS due to unforeseen issues in the laboratory has placed TEDS in a standby mode for the time being. Prior to entering its current standby mode, a limited number of runs were conducted prior to issues arising with the planned operational space for TEDS. This limited the amount of available data for use in the validation of the Dymola model and instead a proof of methodology and concept was shown. Once TEDS resumes normal operation and data becomes available, model validation will be 
enhanced to encompass operational regimes at nominal temperatures and with planned controls and operational modes.

\section{ACKNOWLEDGEMENTS}

This work was supported by the DOE-NE IES program, with work conducted at INL under DOE Operations contract number DE-AC07-05ID14517. 


\section{REFERENCES}

1. Rabiti, C., A. S. Epiney, P. Talbot, J. S. Kim, S. Bragg-Sitton, A. Alfonsi, A. Yigitoglu, S. Greenwood, S. M. Cetiner, F. Ganda, and G. Maronati (2017) "Status Report on Modeling and Simulation Capabilities for Nuclear-Renewable Hybrid Energy Systems," INL/EXT-17-43441, September 2017, Idaho National Laboratory, Idaho Falls, ID, USA.

2. Kim, J. S., M. McKellar, S. Bragg-Sitton, and R. Boardman (2016) "Status Report on the Component Models Developed in the Modelica Framework: High-Temperature Steam Electrolysis \& Gas Turbine Power Plant," INL/EXT-16-40305, Revision 0, October 2016, Idaho National Laboratory, Idaho Falls, ID, USA.

3. Kim, J. S., and K. L. Frick (2018) "Status Report on the Component Models Developed in the Modelica Framework: Reverse Osmosis Desalination Plant \& Thermal Energy Storage," INL/EXT-18-45505, Revision 0, May 2018, Idaho National Laboratory, Idaho Falls, ID, USA.

4. Frick, K. L. (2019) "Status Report on the NuScale Module Development in the Modelica Framework," INL/EXT-19-55520, August 2019, Idaho National Laboratory, Idaho Falls, ID, USA.

5. Dassault Systems (2020) "DYMOLA Systems Engineering [Internet]," [updated 2020 May 28; cited 2018 May 16]. Available at: https://www.3ds.com/products services/catia/products/dymola/.

6. Modelica Association (2018) "Modelica Standard Library [Internet]," [updated 2018 May 22; cited 2018 May 16]. Available at: https://github.com/modelica/Modelica.

7. Greenwood, M.S. (2017) "TRANSFORM - TRANsient Simulation Framework of Reconfigurable Models. Computer Software [Internet]," [updated 2017 Nov. 07]. Oak Ridge National Laboratory, Oak Ridge, TN, USA. Available at: https://github.com/ORNL-Modelica/TRANSFORM-Library.

8. Duenas, A., S. M. Bragg-Sitton, J. S. Yoo, C. M. Stoots, P. Sabharwall, and J. E. O'Brien (2018) "Thermal Energy Delivery System Design Basis Report," INL/EXT-18-51351, Revision 0, September 2018, Idaho National Laboratory, Idaho Falls, ID, USA. https://doi.org/10.2172/1756571.

9. Frick, K., S. Bragg-Sitton, and C. Rabiti (2020) "Modeling the Idaho National Laboratory ThermalEnergy Distribution System (TEDS) in the Modelica ecosystem," Energies, 13, 6353. https://doi.org/10.3390/en13236353.

10. Lew, J., P. Li, C. Chan, W. Karaki, and J. Stephens (2011) "Analysis of heat storage and delivery of a thermocline tank having solid filler material," Journal of Solar Energy Engineering, 133(2), 021003.

11. Esence, T., A. Bruch, S. Molina, B. Stutz, and J.-F. Fourmigué (2018) "A review on experience feedback and numerical modeling of packed-bed thermal energy storage systems," Solar Energy, 153, 628-654. https://doi.org/10.1016/j.solener.2017.03.032.

12. Dynamic Modeling Laboratory (2020) "Dymola User Manual, Full User Manual (All Chapters from User Manual 1A- User Manual 2C Included),” Dynamic Modeling Laboratory. September 2020.

13. Oberkampf, W. L., and C. J. Roy (2010) "Discretization error," In Verification and Validation in Scientific Computing, Cambridge University Press, pp. 286-342.

14. Halachmi, I., A. Dzidic, J. H. Metz, L. Speelman, A. A. Dijkhuizen, and J. P. C. Kleijnen (2001) "Validation of simulation model for robotic milking barn design," European Journal of Operational Research, 134(3), 677-688. https://doi.org/10.1016/S0377-2217(00)00283-6.

15. Hora, J., and P. Campos (2015) "A review of performance criteria to validate simulation models," Expert Systems, 32. https://doi.org/10.1111/exsy.12111.

16. Oberkampf, W. L. \& Roy, C. J. (2010) "Model accuracy assessment," In: Verification and Validation in Scientific Computing, Cambridge University Press, pp. 469-554. 
17. Schwer, L. E. (2007) "Validation metrics for response histories: perspectives and case studies," Engineering with Computers, 23(4), 295-309. https://doi.org/10.1007/s00366-007-0070-1.

18. Rabiti, C., A. Alfonsi, D. Mandelli, J. J. Cogliati, C. Wang, P. W. Talbot, D. P. Malijovec, R. A. Kinoshita, M. G. Abdo, S. Sen, and J. Chen (2021) "RAVEN User Manual," Idaho National Laboratory, Idaho Falls, ID, USA. https://doi.org/10.2172/1784874. 